\title{
Potential Vorticity Diagnostics to Quantify Effects of Latent Heating in Extratropical Cyclones. Part II: Application to Idealized Climate Change Simulations
}

\author{
DOMINIK BÜELER \\ Institute for Atmospheric and Climate Science, ETH Zurich, Zurich, Switzerland, and Institute of Meteorology and \\ Climate Research, Karlsruhe Institute of Technology, Karlsruhe, Germany \\ STEPHAN PFAHL \\ Institute for Atmospheric and Climate Science, ETH Zurich, Zurich, Switzerland, and Institute of Meteorology, \\ Freie Universität Berlin, Berlin, Germany
}

(Manuscript received 23 November 2018, in final form 11 April 2019)

\begin{abstract}
It is still debated how enhanced cloud-condensational latent heating (LH) in a warmer and moister climate may affect the dynamics of extratropical cyclones. In this study, a diagnostic method that explicitly quantifies the contribution of LH to the lower-tropospheric cyclonic potential vorticity (PV) anomaly is used to investigate the effects of stronger LH on the dynamics, intensity, and impacts of cyclones in two conceptually different sets of idealized climate change simulations. A first set of regional surrogate climate change simulations of individual moderate to intense Northern Hemisphere cyclones in a spatially homogeneously 4-Kwarmer climate reveals that enhanced LH can largely but not exclusively explain the substantially varying increase in intensity and impacts of most of these cyclones. A second set of idealized aquaplanet GCM simulations demonstrates that the role of enhanced LH becomes multifaceted for large ensembles of cyclones if climate warming is additionally accompanied by changes in the horizontal and vertical temperature structure: cyclone intensity increases with warming due to the continuous increase in LH, reaches a maximum in climates warmer than present day, and decreases beyond a certain warming once the increase of LH is overcompensated by the counteracting reduction in mean available potential energy. Because of their substantially stronger increase in $\mathrm{LH}$, the most intense cyclones reach their maximum intensity in warmer climates than moderately intense cyclones with weaker LH. This suggests that future projections of the extreme tail of the storm tracks might be particularly sensitive to a correct representation of LH.
\end{abstract}

\section{Introduction}

Extratropical cyclones are a key component of the midlatitude climate as they drive the synoptic weather variability and can cause substantial socioeconomic damages when reaching high intensities associated with strong winds or heavy precipitation (SwissRe 2016). Predicting future changes in the climatological activity of cyclones, the storm tracks, is thus important for regional climate change adaptation in the midlatitudes. However, storm-track predictions are still uncertain for various reasons. Many general circulation models (GCMs) still exhibit problems in representing present-day storm tracks (e.g., Chang et al. 2013; Zappa et al. 2013a),

\footnotetext{
Corresponding author: Dominik Büeler, dominik.bueeler@ kit.edu
}

which introduces uncertainty when projecting them into the future. An important process contributing to these biases is latent heating (LH) due to cloud formation in cyclones (e.g., Colle et al. 2015) because it acts on small- to mesoscales and is thus difficult to capture by the coarse-resolution GCMs (e.g., Champion et al. 2011; Willison et al. 2013, 2015; Trzeciak et al. 2016). The predicted increase of the atmospheric moisture content (e.g., Schneider et al. 2010) will most likely strengthen LH in cyclones and may thus enhance the associated GCM biases. In addition to this, future climate warming is expected to go along with a decrease in lower-tropospheric and increase in upper-tropospheric baroclinicity (e.g., Yin 2005). The strong mutual interaction between LH and the release of baroclinic instability (e.g., Hoskins et al. 1985) further increases uncertainty of storm-track projections 
and complicates understanding the role of $\mathrm{LH}$ in this interplay (e.g., Shaw et al. 2016).

For these reasons, the effects of LH on cyclone dynamics in a changing climate have gained increasing attention. However, in contrast to the well-understood amplifying effect of $\mathrm{LH}$ on cyclone intensification in present-day climate (e.g., Kuo et al. 1991; Davis and Emanuel 1991; Davis 1992; Reed et al. 1993; Stoelinga 1996; Ahmadi-Givi et al. 2004; Čampa and Wernli 2012; Dacre and Gray 2013; Binder et al. 2016; MartínezAlvarado et al. 2016), the effect of enhanced LH on individual cyclones in a warmer and moister climate seems to be less clear: Booth et al. (2013) and Tierney et al. (2018) found more intense cyclones in baroclinic life cycle experiments, in which the atmospheric moisture content was increased either directly or by increasing temperature. In the simulations of Tierney et al. (2018), however, the intensity only increased up to a certain temperature threshold and decreased beyond. Tierney et al. (2018) further demonstrated that this sensitivity to higher temperatures and more moisture also holds with simultaneously increased or reduced troposphereaveraged baroclinicity. Kirshbaum et al. (2018) showed that for a given environmental temperature cyclones in a moist baroclinic life cycle simulation reach higher intensities than their counterparts in the corresponding dry simulation, which is in line with Booth et al. (2013). However, enhanced LH due to increased temperatures was shown to not lead to an additional intensification of their cyclones. They argued that the warm-frontal LH maximum in these warmer simulations shifts more eastward and thus degrades the phasing between drybaroclinically and diabatically induced vertical motion, which even dampens cyclone intensification. Rantanen et al. (2019) found a similar reduction of eddy kinetic energy (EKE) in warmer compared to cooler moist idealized simulations as Kirshbaum et al. (2018), but, in contrast to Kirshbaum et al. (2018), obtained a lower sea level pressure (SLP) minimum. In addition, Rantanen et al. (2019) showed that enhanced LH due to higher environmental temperatures does not increase the intensity of an idealized cyclone when lower-tropospheric baroclinicity is simultaneously reduced, but amplifies cyclone intensification when upper-tropospheric baroclinicity is increased.

These baroclinic life cycle experiments demonstrate that the effect of enhanced LH on cyclone dynamics is equivocal even in a highly idealized setup and, moreover, strongly depends on how exactly the temperature and moisture background states change. Considering this, it is not surprising that the role of enhanced LH for storm tracks in climate simulations, in which an increase in $\mathrm{LH}$ is embedded in various changes in the atmospheric background state, is still not fully understood: Marciano et al. (2015) analyzed U.S. East Coast cyclones from regional surrogate climate change simulations (Schär et al. 1996), in which changes in the atmospheric moisture content were accompanied by changes in baroclinicity. On average, they found an increase in cyclone intensity, which they attributed mainly to enhanced $\mathrm{LH}$ indicated by larger lower-tropospheric potential vorticity (PV) values. The contributions from further thermodynamic changes in their experiments affecting baroclinicity were only weak. Similar conclusions were obtained by Michaelis et al. (2017), but for a substantially larger set of North Atlantic cyclones. In contrast, Bengtsson et al. (2009) and Catto et al. (2011) found no clear evidence for increasing cyclone intensities caused by a strengthening of LH in GCM simulations forced with different greenhouse gas emission scenarios.

To better understand the interaction between the most important physical processes driving the sensitivity of midlatitude storm tracks to climate change, O'Gorman and Schneider (2008a) performed idealized global aquaplanet simulations of a wide range of very cold to very warm climates. They found a nonmonotonic change of mean available potential energy (MAPE) and thus EKE, with a maximum in a climate with a global mean surface air temperature close to present-day Earth and lower values toward colder and warmer climates. This is qualitatively in line with the findings of Tierney et al. (2018). Using the same set of simulations, O'Gorman (2011) demonstrated that MAPE still decreases toward warmer than present-day climates when LH is explicitly accounted for. This is likely due to the fact that stronger poleward and upward latent heat fluxes in cyclones tend to weaken the meridional potential temperature gradient, increase static stability, and consequently decrease MAPE (Schneider et al. 2010). LH thus seems to dampen storm-track intensity on average through its indirect effect on the thermal structure of the atmosphere. Pfahl et al. (2015) analyzed the storm tracks in the same set of simulations but using a cyclone tracking algorithm. They showed that median cyclone intensity, measured in terms of both the lowest SLP minimum and lower-tropospheric relative vorticity along the cyclone tracks, experiences the same nonmonotonic behavior as EKE. However, lower-tropospheric relative vorticity of the most intense cyclones was shown to further increase and peak in climates substantially warmer than presentday Earth, which cannot be explained with the contrasting behavior of MAPE and has thus been hypothesized to result from enhanced LH.

The discussed baroclinic life cycle as well as climate model studies demonstrate that a comprehensive understanding of the role of $\mathrm{LH}$ for future storm tracks 
requires an explicit quantification of $\mathrm{LH}$ in individual cyclones, which allows investigating how the effect of changes in LH depends on further changes in the atmospheric background state. In this study, we follow this approach by applying the PV diagnostic of Büeler and Pfahl (2017), which quantifies the fraction of lower-tropospheric PV resulting from $\mathrm{LH}$ due to cloud-condensational processes, to cyclones from two conceptually different idealized climate change simulations. Cyclone intensity and impacts in terms of surface weather are strongly coupled to the strength of this lower-tropospheric PV anomaly and can thus be linked to LH through the use of this PV diagnostic. First, we perform regional surrogate climate change simulations with a numerical weather prediction (NWP) model of a set of Northern Hemisphere cyclones in a spatially homogeneously warmer climate. These simulations allow us to investigate the effect of enhanced $\mathrm{LH}$ on individual cyclones in a climate, in which only the moisture content changes but baroclinicity stays the same. Second, we use the same set of idealized aquaplanet simulations as in Pfahl et al. (2015) to quantify the effect of LH in more realistic climate change scenarios with spatially heterogeneous temperature changes that are, in addition to changes in the moisture content, accompanied by changes in baroclinicity. Applying the PV diagnostic to the cyclones in these simulations particularly aims to investigate the hypothesis of Pfahl et al. (2015) that the role of increasing LH is different for intense compared to moderate cyclones.

Section 2 briefly summarizes the PV diagnostic and introduces the two different sets of simulations and their underlying models. The adaptation of some input fields and tuning parameters of the PV diagnostic to the two sets of simulations is also described. In section 3 , we quantify the effects of the changes in LH on the cyclones from the two sets of simulations with the use of the PV diagnostic and relate them to changes in cyclone intensity and impacts. Section 4 finishes with a summary and the most important conclusions.

\section{Method}

\section{a. PV diagnostic}

The PV diagnostic by Büeler and Pfahl (2017) quantifies the fraction of the lower-tropospheric PV anomaly in an extratropical cyclone that results from LH due to cloud-condensational processes. To this end, it makes use of a simplified form of the Eulerian PV tendency equation, in which only the two leading terms, diabatic PV modification and vertical advection, are accounted for. This simplification is based on three assumptions, which are reasonable approximations for the lower to middle troposphere and on average over a cyclone area [see Büeler and Pfahl (2017) for more details]: PV is in steady state because of the quasi-balance between the two leading terms, namely, diabatic generation of PV and its upward transport; there is no horizontal PV advection across the boundaries of the cyclone area; and there is no friction. These assumptions ultimately reduce the full PV tendency equation [see Eq. (3) in Büeler and Pfahl (2017)] to a simple balance equation between diabatic PV modification and vertical advection [see Eq. (4) in Büeler and Pfahl (2017)]. Integrating this equation vertically between a lower bound $z_{l}$ (where the PV anomaly is assumed to vanish) and the reference level $z$ yields the so-called diabatic PV, $Q_{\text {diab }}(z)$, which describes the fraction of total lower-tropospheric PV, $Q(z)$, that results from diabatic processes (Büeler and Pfahl 2017) (note that the term "diabatic" here only refers to $\mathrm{LH}$, excluding surface fluxes and radiation):

$$
\begin{aligned}
& \left\langle Q_{\text {diab }}(z)\right\rangle_{\text {effarea }} \\
& \quad=\int_{z_{1}}^{z}\left\langle\frac{1}{\rho}\left(\eta_{x} \frac{\partial \dot{\theta}}{\partial x}+\eta_{y} \frac{\partial \dot{\theta}}{\partial y}+\eta_{z} \frac{\partial \dot{\theta}}{\partial z}\right) \frac{1}{w} d z\right\rangle_{w \geq W, \text { effarea }} .
\end{aligned}
$$

Here, $\rho$ is the density, $\eta_{x}, \eta_{y}$, and $\eta_{z}$ are the $x, y$, and $z$ components of the absolute vorticity, $\dot{\theta}$ is the potential temperature tendency, and $w$ is the vertical wind velocity. The term in the angle brackets is averaged over all grid points inside an effective cyclone area [including the major frontal features; see Büeler and Pfahl (2017, section $2 \mathrm{e}$ ), for more details] with a vertical wind velocity $w$ larger than the threshold $W$, which assures that only regions with substantial upward motion are accounted for.

Büeler and Pfahl (2017) have demonstrated that this PV diagnostic is able to capture particularly the mean but also parts of the strong case-to-case variability of the sensitivity of the lower-tropospheric PV anomaly to LH in an ensemble of cyclones. It is thus a useful tool to systematically quantify the effect of LH on cyclone dynamics in a climatological framework, as it is done in this study.

\section{b. COSMO surrogate climate change simulations}

\section{1) PRinciple AND MOdel Simulations}

The surrogate climate change or pseudowarming simulation method has been developed by Schär et al. (1996) and used in numerous subsequent studies (e.g., Frei et al. 1998; Marciano et al. 2015; Lackmann 2015; Michaelis et al. 2017; Sandvik et al. 2018). Its underlying idea is to simulate the response of regional weather or 
climate to a large-scale change in temperature. This allows studying the thermodynamic effect of climate change and its associated feedbacks (as for instance through changing LH). Technically, this is achieved by adding a temperature change $\Delta T$ to each grid point of the initial and lateral boundary fields of a reference simulation with a regional model. Thereby the relative humidity is kept constant and the specific humidity consequently scales according to the Clausius-Clapeyron relationship, which is consistent with what observations and models indicate for a warmer climate (e.g., Held and Soden 2006; Sherwood and Meyer 2006).

Following the same principle, we perform surrogate climate change simulations with the regional Consortium for Small-Scale Modeling (COSMO) NWP model (Steppeler et al. 2003) of 12 Northern Hemisphere cyclones, which have already been studied in Büeler and Pfahl (2017, see their Table 1) and represent a broad spectrum of moderate to very intense cases. Our horizontally and vertically uniform perturbation $\Delta T$ is $+4 \mathrm{~K}$ [this includes the stratosphere; that is, the projected lower-stratospheric cooling (e.g., Shindell et al. 1998) is not accounted for], which is consistent with the predicted end-of-century global mean surface air temperature change under the RCP8.5 scenario (e.g., Knutti and Sedláček 2013). To preserve hydrostatic balance, the pressure field is adjusted by integrating the hydrostatic equation from the bottom to the top of the atmosphere using the new temperature field $T+\Delta T$ (e.g., Kröner et al. 2017). The sea and land surface temperatures are increased accordingly to keep the same vertical temperature gradient between the surface and the atmosphere. Beside these perturbations, the model setup and cyclone tracking are the same as for the reference simulations performed by Büeler and Pfahl (2017, see their section 2a): they are run on a rotated geographical grid with a horizontal spacing of $0.125^{\circ}(\sim 14 \mathrm{~km})$ and 40 vertical levels. Hereafter, the simulations with a 4-K-higher temperature are denoted "warm simulations."

\section{2) INPUT FIELDS AND SETTINGS OF THE PV DIAGNOSTIC}

The PV diagnostic by Büeler and Pfahl (2017) requires instantaneous potential temperature tendencies at each grid point. Here, we calculate these tendencies following Berrisford (1988) and Wernli (1995) [Büeler and Pfahl 2017, Eq. (7)] instead of using the tendencies from the model output as it has been done in Büeler and Pfahl (2017). The reason for this is described in detail in Büeler (2017, section 3.2.4). Applying the PV diagnostic with such diagnosed potential temperature tendencies has been shown to yield qualitatively and quantitatively similar results as with tendencies obtained directly from the model (Büeler and Pfahl 2017). The effective cyclone area and the vertical wind velocity threshold $W$ in Eq. (1) are defined in the same way as in Büeler and Pfahl (2017) (i.e., $W=2 \times 10^{-2} \mathrm{~m} \mathrm{~s}^{-1}$ ).

\section{c. Idealized GCM simulations}

\section{1) Model Description AND Simulations}

We use the same simulations as Pfahl et al. (2015), which are based on an idealized GCM comparable to that of Frierson et al. (2006) and have been performed in an aquaplanet setup similar to O'Gorman and Schneider (2008a). By changing the optical thickness of the atmosphere (through a varying scaling parameter; see O'Gorman and Schneider 2008b; Pfahl et al. 2015), a range of very cold to very warm climates is simulated with global mean surface air temperatures $T_{G}$ ranging from 270 to $316 \mathrm{~K}$. The $T_{G}$ in the reference simulation is $288 \mathrm{~K}$, which is similar to present-day Earth. The simulations have been run with a spectral horizontal resolution of T85 ( $\sim 235 \mathrm{~km}$ at the equator) and 30 vertical sigma levels. Each simulation had been spun up for 300 days and then run by another 300 days ( 900 days for the simulations with $T_{G}=270,288$, and $311 \mathrm{~K}$ ) as a basis for the statistical analysis. The resulting set of 15 simulations allows us to investigate variations in the effects of LH on cyclones in strongly different climates.

\section{2) CYCLONE IDENTIFICATION, TRACKING, AND SELECTION}

We identify and track cyclones based on the SLP field as in Pfahl et al. (2015), using an adapted version of the method by Wernli and Schwierz (2006). To account for extratropical and long-living cyclones only, we extract all cyclone tracks whose lowest SLP minimum is located within $30^{\circ}-80^{\circ}$ north or south and whose lifetime is $24 \mathrm{~h}$ or longer. From each simulation, we select two cyclone subsets, namely, the "intense cyclones" and the "moderate cyclones," whereby the lowest SLP minimum along a cyclone track is used as the intensity measure (see Pfahl et al. 2015). The first subset (intense cyclones) consists of the 100 most intense cyclones of the 300-day simulations and the 300 most intense cyclones of the 900-day simulations (i.e., the simulations with $T_{G}=270,288$, and $311 \mathrm{~K}$ ). For the second subset (moderate cyclones), the 100 or 300 cyclones, respectively, are selected whose intensity is closest to the median intensity of all cyclones in the simulation. If instead a fixed percentile of $5 \%$ is used to define the two cyclone subsets (which yields sample sizes slightly smaller than 100 or 300 , respectively), qualitatively very similar results are obtained (not shown). To test the sensitivity of our results to the intensity measure used to define the two cyclone subsets, we additionally 
perform the same analysis for equally large subsets of intense and moderate cyclones defined in terms of lower-tropospheric relative vorticity. To this end, relative vorticity on $\sim 838 \mathrm{hPa}$ is averaged in a radius of $300 \mathrm{~km}$ around the SLP minimum along the cyclone track and the maximum of this area-averaged vorticity for each track is used as a basis to select the intense and moderate cyclones.

\section{3) INPUT FIELDS AND SETTINGS OF THE PV DIAGNOSTIC}

We calculate Ertel PV using Eq. (1) of Pfahl et al. (2015). The climatological PV strongly differs between the different climates of the idealized GCM simulations (Büeler 2017, their Figs. 4.3 and 4.4). Therefore, PV anomalies are calculated for every cyclone with respect to the corresponding PV climatology to allow for a quantitative comparison of the cyclones' lower-tropospheric PV among the climates. The underlying PV climatologies are calculated by neglecting all grid points inside a cyclone area, which prevents including a bias from cyclonic, potentially diabatic, $\mathrm{PV}$ in the background state.

As for the COSMO surrogate climate change simulations, the potential temperature tendencies are calculated following Berrisford (1988) and Wernli (1995). The effective cyclone areas are calculated as in Büeler and Pfahl (2017), but with parameters adapted to the lower GCM resolutions [see Büeler (2017, section 4.2.2) for more details]. To account for small or weak cyclones, a circle with a radius of $350 \mathrm{~km}$ [identical to Pfahl et al. (2015)] around the relative vorticity maximum (or around the SLP minimum if the relative vorticity maximum is farther away than $600 \mathrm{~km}$ from the SLP minimum) is chosen as a minimum extent of the effective cyclone area.

As briefly discussed in Büeler and Pfahl (2017), the amplitude of our diagnosed diabatic PV is sensitive to some of the underlying thresholds. Since the coarser horizontal and vertical resolutions of the idealized GCM compared to COSMO go along with weaker vertical wind velocities, these thresholds have to be adapted. For this purpose, we have calculated the median diabatic PV profile for the intense cyclones of the reference simulation $\left(T_{G}=288 \mathrm{~K}\right)$ using different combinations of lower integration bound and vertical wind velocity threshold $W$. Based on this sensitivity test, we have chosen the third-lowest model level $(\sim 929 \mathrm{hPa})$ as the lower integration bound and a vertical wind velocity threshold $W$ of $5 \times 10^{-3} \mathrm{~m} \mathrm{~s}^{-1}$, which yields the physically most consistent diabatic PV profiles [see Büeler (2017, section 4.2.5), for more details]. For consistency, this combination of thresholds is used for the intense and moderate cyclone subsets of all simulations.

\section{Results}

a. COSMO surrogate climate change simulations

\section{1) CyClone CHARACTERISTiCs}

The changes in temperature and thus in moisture content in the COSMO surrogate climate change simulations lead to a variety of changes in cyclone structure, intensity, and impacts. They are discussed in detail in Büeler (2017, section 3.3.2) and summarized here. Thereby, the changes in the warm compared to the reference simulations always refer to a spatial average over the effective cyclone areas (except for the SLP minimum) and a temporal average over the last $18 \mathrm{~h}$ of the intensification phase (i.e., before the time of the lowest SLP minimum). All cyclones experience reduced SLP minimum values in the warm simulation averaged over these last $18 \mathrm{~h}$, but there is a strong variation in the reduction among the cyclones ranging from less than $1 \mathrm{hPa}$ to almost $5 \mathrm{hPa}$. The average SLP minimum sensitivity amounts to $-0.6 \mathrm{hPa} \mathrm{K}^{-1}$. Lower-tropospheric relative vorticity increases in most cyclones, but stays approximately unchanged or even decreases slightly in some cyclones, yielding an average relative vorticity sensitivity of $0.5 \% \mathrm{~K}^{-1}$. This implies that all cyclones experience an intensity increase in the warm simulations as measured by the SLP minimum, which, however, is not necessarily associated with an increase in lower-tropospheric relative vorticity.

The changes in total precipitation in the warm simulations are positive for all cyclones but vary strongly. The increase in total precipitation averaged over all cyclones amounts to $6.3 \% \mathrm{~K}^{-1}$ and is thus smaller than the increase in total precipitable water $\left(8.8 \% \mathrm{~K}^{-1}\right)$ as well as in near-surface water vapor $\left(7.4 \% \mathrm{~K}^{-1}\right)$. This indicates that the cyclones in the warmer simulations are slightly less efficient in producing precipitation. The reason for this and whether this is a robust signal would require further investigation of the whole cyclone life cycles. The maximum wind gusts at $10 \mathrm{~m}$ increase in all cyclones except one. Averaging over all cyclones yields a maximum wind gust sensitivity of $0.8 \% \mathrm{~K}^{-1}$, which is smaller than for the precipitation amount.

Almost all the discussed changes in intensity and impacts show a consistent sign, even though the variations among cyclones are substantial. The results are also consistent with previous studies based on baroclinic life cycle experiments (e.g., Kirshbaum et al. 2018; Rantanen et al. 2019; Tierney et al. 2018) and regional surrogate climate change simulations (e.g., Marciano et al. 2015; Michaelis et al. 2017). We hereafter use our PV diagnostic to quantify to what degree enhanced LH can explain the mean as well as the strong case-to-case variability of these changes. 

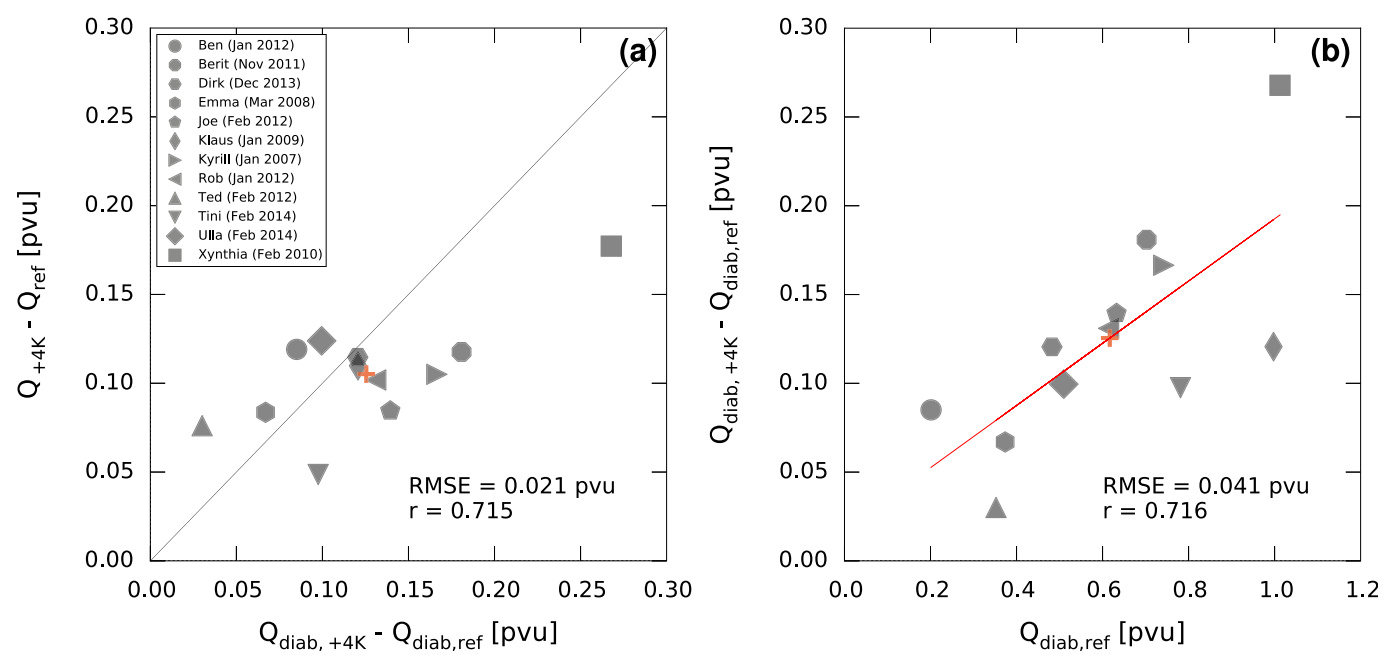

FIG. 1. (a) Difference between the warm and the reference simulations of the mass-weighted vertical averages between 950 and $600 \mathrm{hPa}$ of diabatic PV $\left(Q_{\text {diab },+4 \mathrm{~K}}-Q_{\text {diab,ref }}\right.$; PVU; $x$ axis $)$ and total PV $\left(Q_{+4 \mathrm{~K}}-Q_{\text {ref }} ; \mathrm{PVU} ; y\right.$ axis $)$ for the 12 different cyclones. (b) Mass-weighted vertical average between 950 and $600 \mathrm{hPa}$ of diabatic PV in the reference simulations $\left(Q_{\text {diab,ref }} ; \mathrm{PVU} ; x\right.$ axis) and $Q_{\text {diab, }+4 \mathrm{~K}}-Q_{\text {diab,ref }}(\mathrm{PVU} ; y$ axis) for the same cyclones. Temporal averages over the last three time steps of the intensification phase are shown $(12 \mathrm{~h}$ before, $6 \mathrm{~h}$ before, and at the time of the lowest SLP minimum). The red cross indicates the average over the whole cyclone ensemble, the diagonal black line in (a) shows the identity line $(y=x)$, and the red line in (b) shows a linear regression line. The root-meansquare errors (RMSEs) and Pearson correlation coefficients $r$ are also indicated.

\section{2) EFFECTS OF LATENT HEATING ON CYCLONE PV, INTENSITY, AND IMPACTS}

Figure 1a summarizes the results of our PV diagnostic for the 12 cyclones. It shows the sensitivity of lowertropospheric total $\mathrm{PV}$ to temperature as obtained from the model experiments $\left(Q_{+4 \mathrm{~K}}-Q_{\text {ref }} ; \mathrm{PV}\right.$ units; $1 \mathrm{PVU}=$ $10^{-6} \mathrm{~K} \mathrm{~m}^{2} \mathrm{~kg}^{-1} \mathrm{~s}^{-1}$ ) plotted against the sensitivity of lower-tropospheric diabatic PV diagnosed by the PV diagnostic $\left(Q_{\text {diab },+4 \mathrm{~K}}-Q_{\text {diab,ref }}\right)$. The sensitivity values are obtained from the mass-weighted vertical average of the $Q$ and $Q_{\text {diab }}$ profiles (which themselves are calculated over the effective cyclone areas; see Büeler 2017, Fig. 3.13) between 950 and $600 \mathrm{hPa}$, temporally averaged over the last $18 \mathrm{~h}$ of the intensification phase. Different combinations of the two vertical pressure boundaries have been shown to not change the results of the PV diagnostic notably for the cyclone ensemble used here (Büeler and Pfahl 2017). The modeled lower-tropospheric total PV increases in the warm simulation of all cyclones $\left(Q_{+4 \mathrm{~K}}-Q_{\text {ref }}\right)$. Cyclone Xynthia is most sensitive among all cyclones; Cyclones Ulla, Ben, Berit, Dirk, Klaus, Kyrill, and Rob have a moderate sensitivity; and $\mathrm{Cy}-$ clones Joe, Emma, Ted, and Tini are the least sensitive. The modeled sensitivity of the most sensitive Cyclone Xynthia is more than 3.5 times larger than the one of the least sensitive Cyclone Tini, which demonstrates the strong case-to-case variability. Overall, the sensitivity diagnosed by our PV diagnostic $\left(Q_{\text {diab },+4 \mathrm{~K}}-Q_{\text {diab,ref }}\right)$ agrees reasonably well with the corresponding modeled sensitivity (correlation coefficient $r=0.72$, root-meansquare error of $0.02 \mathrm{PVU}$ ). The mean modeled sensitivity of the whole cyclone ensemble is $0.11 \mathrm{PVU}$ and thus very similar to the mean diagnosed sensitivity of 0.13 PVU. This demonstrates that the increase of lowertropospheric $\mathrm{PV}$ in a 4-K-warmer climate as well as its strong variability among cyclones can largely be explained with the increase in lower-tropospheric diabatic PV generation due to stronger LH associated with the higher moisture content. Nevertheless, there are cyclones for which the PV diagnostic overestimates and others for which it underestimates the modeled sensitivity. These mismatches likely result from the imperfectness of our PV diagnostic rather than from changes in other, adiabatic, frictional, or radiative, processes affecting lower-tropospheric PV. This conclusion is supported by the fact that the correlation coefficient obtained from the verification of our PV diagnostic based on sensitivity simulations, in which LH has been modified directly by altering the latent heat constants in the model ( $r=0.71$; see Büeler and Pfahl 2017, Fig. 10), is almost equal to the correlation coefficient obtained here ( $r=0.72$; see Fig. 1a). Figure 1b illustrates how the increase in diabatic PV generation with temperature relates to the importance of diabatic processes in the reference simulation as measured by diagnosed diabatic $\mathrm{PV}\left(Q_{\text {diab,ref }}\right)$. The correlation of $r=0.72$ demonstrates 

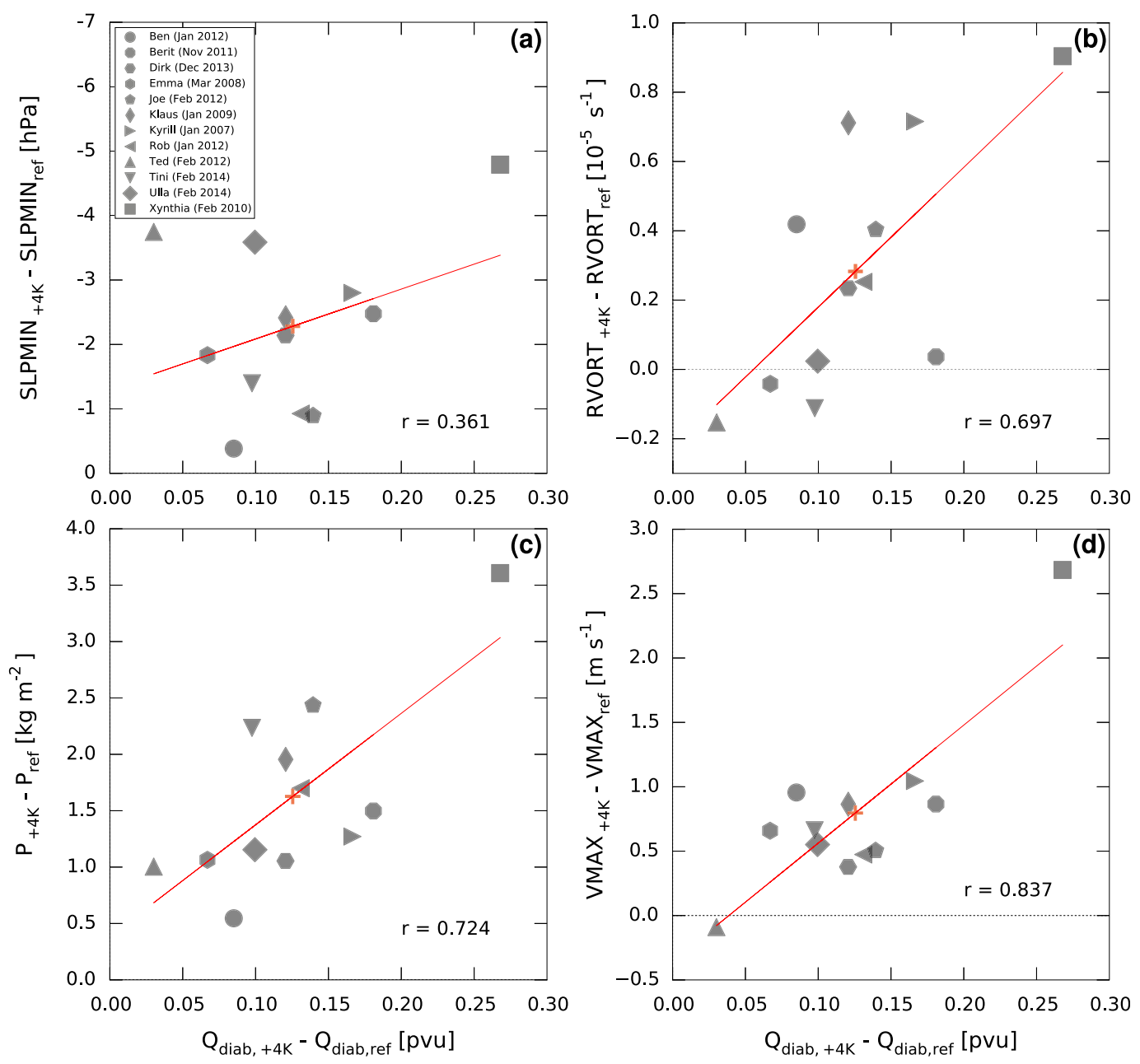

FIG. 2. Difference between the warm and the reference simulations of the mass-weighted vertical averages between 950 and $600 \mathrm{hPa}$ of diabatic PV (PVU) on the $x$ axes and difference between the warm and the reference simulations of (a) the SLP minimum ( $\mathrm{hPa}$ ) along the cyclone track, (b) lower-tropospheric relative vorticity $\left(10^{-5} \mathrm{~s}^{-1}\right.$; at $\left.850 \mathrm{hPa}\right)$, (c) 6-h accumulated total precipitation $\left(\mathrm{kg} \mathrm{m}^{-2}\right)$, and (d) maximum wind gusts at $10 \mathrm{~m}$ $\left(\mathrm{m} \mathrm{s}^{-1}\right)$ on the $y$ axes. Lower-tropospheric relative vorticity, total precipitation, and maximum wind gusts at $10 \mathrm{~m}$ are averaged over the effective cyclone area. Temporal averages over the three last time steps of the intensification phase are shown ( $12 \mathrm{~h}$ before, $6 \mathrm{~h}$ before, and at the time of the lowest SLP minimum). The red crosses and lines are as in Fig. 1. The Pearson correlation coefficients $r$ are also indicated.

that the temperature sensitivity of lower-tropospheric diabatic PV is stronger for cyclones with a larger diabatic PV anomaly in the reference simulation. This implies that strongly diabatically driven cyclones in present-day climate, as for instance Cyclone Xynthia, are more sensitive to an increase in $\mathrm{LH}$.

Figures $2 \mathrm{a}$ and $2 \mathrm{~b}$ illustrate how the changes in lowertropospheric diabatic PV due to changes in $\mathrm{LH}$, shown in Fig. 1a, relate to changes in cyclone intensity. Figure 2a compares the temperature sensitivity of lower-tropospheric diabatic PV to the temperature sensitivity of the SLP minimum [see section $3 \mathrm{a}(1)$ ], averaged over the last $18 \mathrm{~h}$ of the intensification phase. The correlation between the two sensitivities is weak $(r=0.36)$, which means that the changes in lower-tropospheric diabatic PV can hardly explain the case-to-case variability of SLP minima changes in the warm simulations. This implies that beside enhanced LH (and thus stronger lower-tropospheric diabatic PV generation) further dynamical effects might contribute to the reduction of the SLP minima along the cyclone tracks in the warm simulations. As shown in Fig. 2b, the correlations are higher $(r=0.7)$ when defining cyclone intensity in terms of lower-tropospheric relative vorticity [see section $3 \mathrm{a}(1)$ ], which demonstrates that enhanced LH is the main driver for the increase in this intensity measure. This highlights the importance of considering different intensity measures to investigate effects of stronger LH on cyclone intensity. Figures $2 \mathrm{c}$ 
and $2 \mathrm{~d}$ show how the changes in lower-tropospheric diabatic PV due to changes in LH relate to changes in cyclone impacts. Figure $2 \mathrm{c}$ compares the temperature sensitivity of lower-tropospheric diabatic PV to the temperature sensitivity of total precipitation [see section $3 \mathrm{a}(1)]$, averaged over the last $18 \mathrm{~h}$ of the intensification phase. The high correlation $(r=0.72)$ between the two sensitivities is due to the fact that precipitation is directly linked to LH. It demonstrates that precipitation can be used as a reasonable first-order proxy to quantify $\mathrm{LH}$ in cyclones of a warmer climate. Figure $2 \mathrm{~d}$ compares the temperature sensitivity of lower-tropospheric diabatic $\mathrm{PV}$ to the temperature sensitivity of maximum wind gusts at $10 \mathrm{~m}$ [see section $3 \mathrm{a}(1)$ ]. There is also a high correlation $(r=0.84)$, which mainly results from the direct physical link between wind velocity and PV through relative vorticity (see Fig. 2b) and thus indicates an important role of LH also for changes in near-surface wind gusts.

The relationships discussed above, however, have to be interpreted with caution because of the rather small sample size, which makes the correlations sensitive to outliers. For instance, removing the strong outlier (Xynthia) from the cyclone ensemble in Figs. 2c and $2 \mathrm{~d}$ results in substantially weaker correlations between the temperature sensitivities in both cases: the correlation coefficients reduce to $r=0.39$ between lower-tropospheric diabatic PV and total precipitation and to $r=0.59$ between lower-tropospheric diabatic PV and maximum wind gusts at $10 \mathrm{~m}$. Removing the other outlier (Ted) hardly affects the correlations, whereas the removal of both outliers further reduces them.

Despite these partly nonrobust correlations, the application of our PV diagnostic to an ensemble of $12 \mathrm{cy-}$ clones demonstrates that enhanced LH is an important driver for the changes in the dynamics, intensity, and impacts of individual cyclones in a spatially homogeneously warmer climate. Although these changes strongly vary from case to case, they are relatively robust with respect to the sign and thus indicate a robust tendency both for moderate and intense cyclones. To understand to what degree this relationship holds for a larger ensemble of cyclones and in a more realistic climate change scenario, we hereafter investigate the effects of LH on cyclones in idealized GCM simulations.

\section{b. Idealized GCM simulations}

\section{1) Climate characteristics}

The set of simulations obtained by perturbing the optical thickness of the idealized GCM [see section $2 \mathrm{c}(1)$ ] yields a spectrum of climates that is associated with various changes in the thermal structure of the midlatitude atmosphere, which can be summarized as follows (O'Gorman and Schneider 2008a; Pfahl et al. 2015): the midlatitude meridional temperature gradient, vertically averaged throughout the troposphere, decreases from the coldest to the warmest climate. This decrease is mainly driven by the lower troposphere, because in the middle and upper (particularly subtropical) troposphere the meridional temperature gradient increases toward warmer climates. Vertically averaged dry static stability experiences a nonmonotonic change, with the highest values in the coldest and warmest climates and the minimum close to the reference climate $\left(T_{G}=\right.$ $288 \mathrm{~K})$. The depth of the troposphere increases from the coldest to the warmest climate. The changes of these three structural measures result in a nonmonotonic behavior of MAPE, with a maximum in the climates slightly colder than the reference climate and a minimum in the coldest and warmest climates.

\section{2) CYCLONE CHARACTERISTICS}

Figures 3 and 4 illustrate the sensitivity of some properties of the moderate and intense cyclones defined in terms of the SLP minimum [see section 2c(2) for details about the selection criteria]. Figure 3 a indicates the latitudinal distribution of the two cyclone subsets: overall, the intense cyclones are located more poleward than the moderate cyclones, particularly in the colder climates. In contrast to the moderate cyclones, the intense cyclones do not reach more equatorward than $50^{\circ}$. Figure $3 \mathrm{~b}$ shows that the size of the effective cyclone areas, which correlates with cyclone intensity due to its definition based on relative vorticity (Büeler and Pfahl 2017, section 2e), is larger for the intense than for the moderate cyclones on average. There are also size differences among climates within the two cyclone subsets. These variations between intense and moderate cyclones as well as among climates can be problematic because the magnitude of a variable averaged over larger cyclone areas might be negatively biased in comparison to the magnitude of a variable averaged over smaller cyclone areas. This is because the spatial average over larger cyclone areas includes more grid points where the variable tends to be relatively small (for instance, high magnitudes of lower-tropospheric PV, relative vorticity, or precipitation are typically concentrated near the cyclone center and along the fronts but decrease further away). A pragmatic way to reduce this bias is to rescale the averaged scalar of every climate with its relative effective cyclone area size. This can be done as follows:

$$
\chi_{c}^{\text {rescaled }}=\chi_{c} A_{c}^{\mathrm{rel}},
$$

where $\chi_{c}^{\text {rescaled }}$ denotes the rescaled area-averaged value for the climate $c, \chi_{c}$ is the corresponding original 

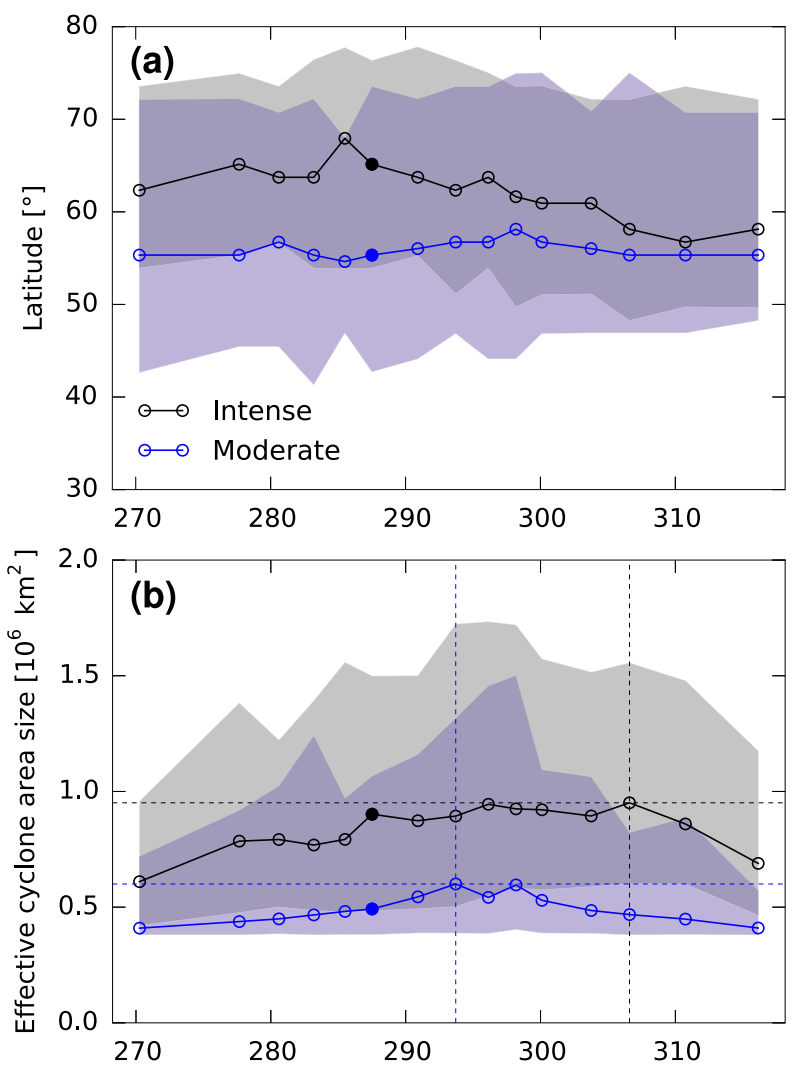

FIG. 3. Spatial characteristics of the SLP-based intense (black) and moderate cyclones [blue; see section $2 \mathrm{c}(2)$ ] at the time of their SLP minima as a function of global mean surface air temperature (K): (a) latitude ( $\left.{ }^{\circ} \mathrm{N} / \mathrm{S}\right)$ of the SLP minimum and (b) effective cyclone area size $\left[10^{6} \mathrm{~km}^{2}\right.$; note that by construction it has a lower bound determined by the minimum radius of $350 \mathrm{~km}$; cf. section $2 c(3)]$. The lines show the median, and the shading indicates the range between the 5 th and 95 th percentiles. The filled circles indicate the median for the reference climate $\left(T_{G}=288 \mathrm{~K}\right)$. Vertical dashed lines in (b) indicate the climate, in which the minimum or maximum of the displayed variable, shown by the horizontal dashed lines, is reached.

area-averaged value, and $A_{c}^{\mathrm{rel}}=A_{c} / A_{\min }$ is the nondimensional relative effective cyclone area size of the climate $c$, with $A_{c}$ denoting the median effective cyclone area size of the climate $c$ and $A_{\min }=\pi(350 \mathrm{~km})^{2}$ the minimum possible effective cyclone area size. Analyzing

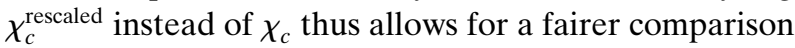
both between climates but also between moderate and intense cyclones within a climate. This rescaling is applied hereafter to the area-averaged cyclone characteristics fields displayed in Fig. 4.

Figure 4a shows cyclone intensity measured in terms of the lowest SLP minimum. It changes nonmonotonically with temperature, with a minimum in climates close to the reference climate $\left(T_{G}=294 \mathrm{~K}\right.$ for the moderate and $T_{G}=$ $286 \mathrm{~K}$ for the intense cyclones) and maxima in the coldest and warmest climates (see also Pfahl et al. 2015, their Fig. 4b). Using relative vorticity in the lower troposphere $(\sim 838 \mathrm{hPa})$ averaged over the effective cyclone area as intensity measure, as shown in Fig. $4 \mathrm{~b}$, yields qualitatively the same nonmonotonic pattern for the moderate cyclones, with an intensity maximum in the same, slightly warmer than present-day climate $\left(T_{G}=\right.$ $294 \mathrm{~K}$ ). For the intense cyclones, however, the nonmonotonic pattern changes substantially and reaches the highest intensity in a much warmer climate $\left(T_{G}=\right.$ $307 \mathrm{~K}$ ), which is in line with Fig. 14c of Pfahl et al. (2015). The nonmonotonic pattern looks qualitatively very similar if lower-tropospheric relative vorticity is not rescaled following Eq. (2), although the differences among climates and between the moderate and intense cyclones (particularly in the warmer climates) are substantially smaller (not shown). Figure $4 \mathrm{c}$ shows cyclone-related precipitation, which is accumulated over $6 \mathrm{~h}$ before the time of the cyclones' lowest SLP minima. It is small in the climates colder than the reference climate $\left(T_{G}=\right.$ $288 \mathrm{~K}$ ) for both cyclone subsets. This is consistent with a small cyclone-related vertically integrated water vapor in the cold climates (not shown). Toward warmer climates, precipitation increases slightly for the moderate cyclones but substantially for the intense cyclones. The maximum is reached in climates much warmer than present-day Earth for both cyclone subsets, followed by a decrease toward the warmest climate. This decrease is in contrast to the further increase of cyclone-related vertically integrated water vapor toward the warmest climate due to the Clausius-Clapeyron relationship (not shown). Evaluating precipitation accumulated $6 \mathrm{~h}$ before the time of maximum precipitation (obtained by averaging precipitation in a radius of $1000 \mathrm{~km}$ around the SLP minimum along the cyclone track) yields qualitatively similar results as Fig. 4c, except that the increase toward warmer climates is stronger, particularly for the intense cyclones (not shown). Interestingly, the average time between maximum precipitation and the lowest SLP minimum, which is substantially larger for the intense than for the moderate cyclones, changes considerably with $T_{G}$, with a minimum in climates with $T_{G}$ between 290 and $300 \mathrm{~K}$ and two maxima in the coldest and warmest climates. An increase in cyclonerelated precipitation with climate warming has also been found in comprehensive GCM simulations (e.g., Bengtsson et al. 2009; Yettella and Kay 2017). Nearsurface wind speed, shown in Fig. 4d, behaves almost identically to cyclone intensity measured in terms of lowertropospheric relative vorticity (Fig. 4b), with a maximum reached in a climate slightly warmer than present-day for the moderate cyclones and in a substantially warmer climate for the intense cyclones. 

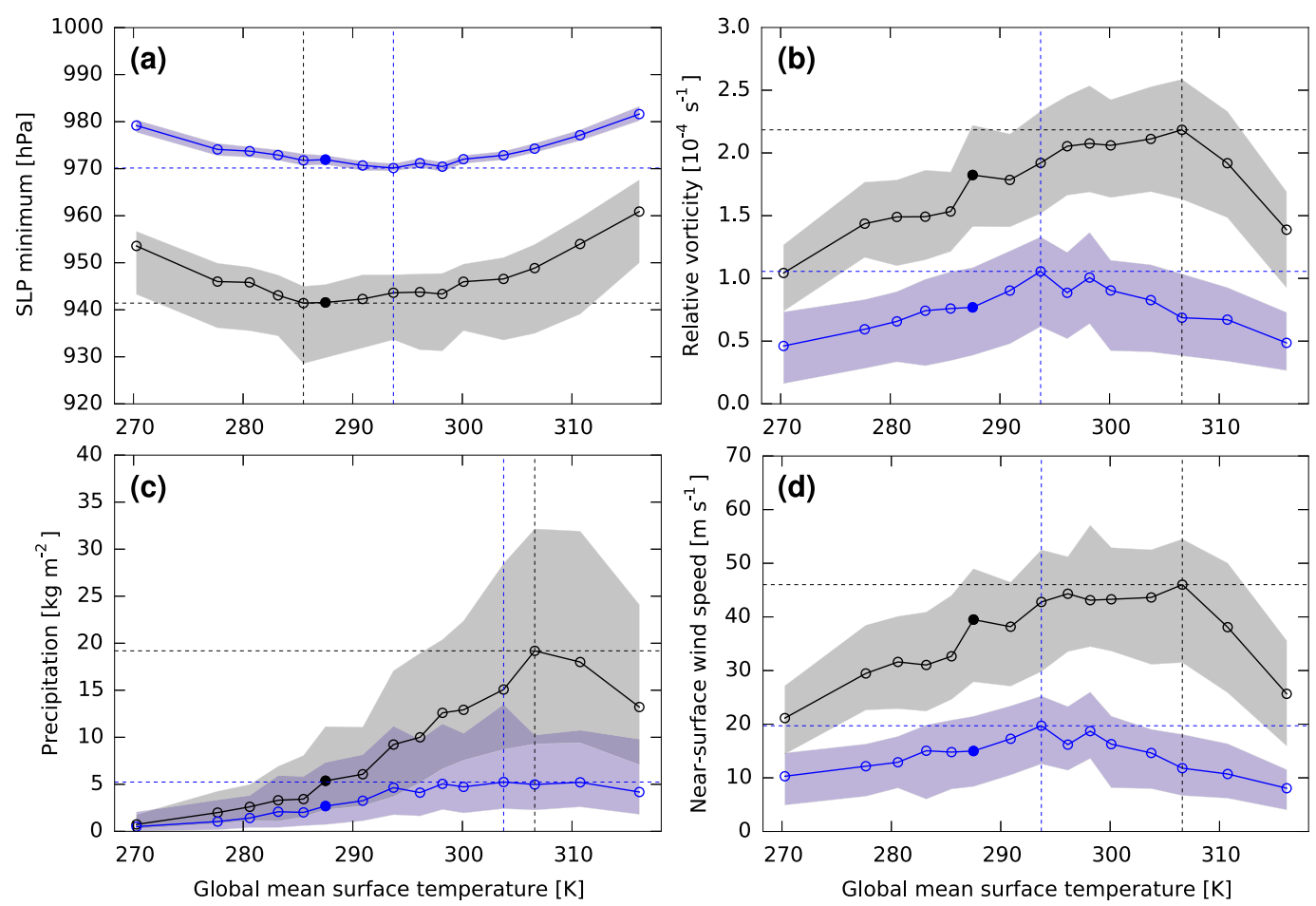

FIG. 4. As in Fig. 3, but for different intensity and impact fields: (a) SLP minimum (hPa), (b) lower-tropospheric $(\sim 838 \mathrm{hPa})$ relative vorticity $\left(10^{-4} \mathrm{~s}^{-1}\right)$, (c) 6-h accumulated total precipitation $\left(\mathrm{kg} \mathrm{m}^{-2}\right)$, and (d) wind speed $\left(\mathrm{m} \mathrm{s}^{-1}\right)$ at the lowest model level $(\sim 989 \mathrm{hPa})$. The variables in (b)-(d) are averaged over the effective cyclone areas and rescaled following Eq. (2).

In the following, we use our PV diagnostic to investigate the role of $\mathrm{LH}$ for these nonmonotonic changes in cyclone intensity and impacts with $T_{G}$.

\section{3) EFFECTS OF LATENT HEATING ON CYCLONE PV, INTENSITY, AND IMPACTS}

Figure 5 shows the vertical profiles of the modeled total PV anomaly $Q$ (with respect to the PV climatology of the respective climate; hereafter denoted "PV anomaly") and diagnosed diabatic PV $Q_{\text {diab }}$ [(hereafter denoted "diabatic PV"; Eq. (1)] for the SLP-based moderate (Figs. 5a-h) and intense (Figs. 5i-p) cyclones of some selected climates. The profiles are averaged over the effective cyclone areas at the time of the cyclones' lowest SLP minima.

The median PV anomaly profile of the moderate and intense cyclones in the reference simulation (Figs. 5d,1) is qualitatively similar to the PV profile of cyclones in ERA-Interim analyzed by Čampa and Wernli (2012, see their Fig. 3), particularly in the lower and middle troposphere (see also Pfahl et al. 2015). For the intense cyclones, PV values are approximately 0.2 PVU higher than for the moderate cyclones throughout the troposphere and the lower-tropospheric maximum extends to slightly higher altitudes. Both structure and amplitude of the PV anomaly profiles change substantially with
$T_{G}$ : in the cold climates (Figs. 5a-c,i-k), the lowertropospheric maximum is smaller and restricted to very low levels. The midtropospheric minimum is located at lower levels between 850 and $600 \mathrm{hPa}$ and becomes slightly negative, particularly in the moderate cyclones. Also the upper-tropospheric maximum is weaker and located at considerably lower levels. This overall reduction of the vertical extent of the cyclones is primarily a result of the reduced tropospheric depth in the cold climates [see section $3 b(1)]$. The difference in amplitude between the intense and the moderate cyclones throughout the troposphere still amounts to approximately $0.2 \mathrm{PVU}$. Toward warmer climates (Figs. 5e-h,m-p), the lowertropospheric maximum increases in amplitude and extends more into the middle troposphere, at the cost of the midtropospheric minimum that gradually vanishes. Also the upper-tropospheric maximum occurs at higher levels. In the warmest climates, the positive PV anomaly spans the whole troposphere. This increase in vertical extent of the cyclones reflects the increase in tropospheric depth toward the warmer climates [see section $3 b(1)]$. The difference between the amplitudes of the intense and the moderate cyclones reaches up to 0.4 PVU in the warmer climates and is thus larger than in the colder climates in absolute terms. 

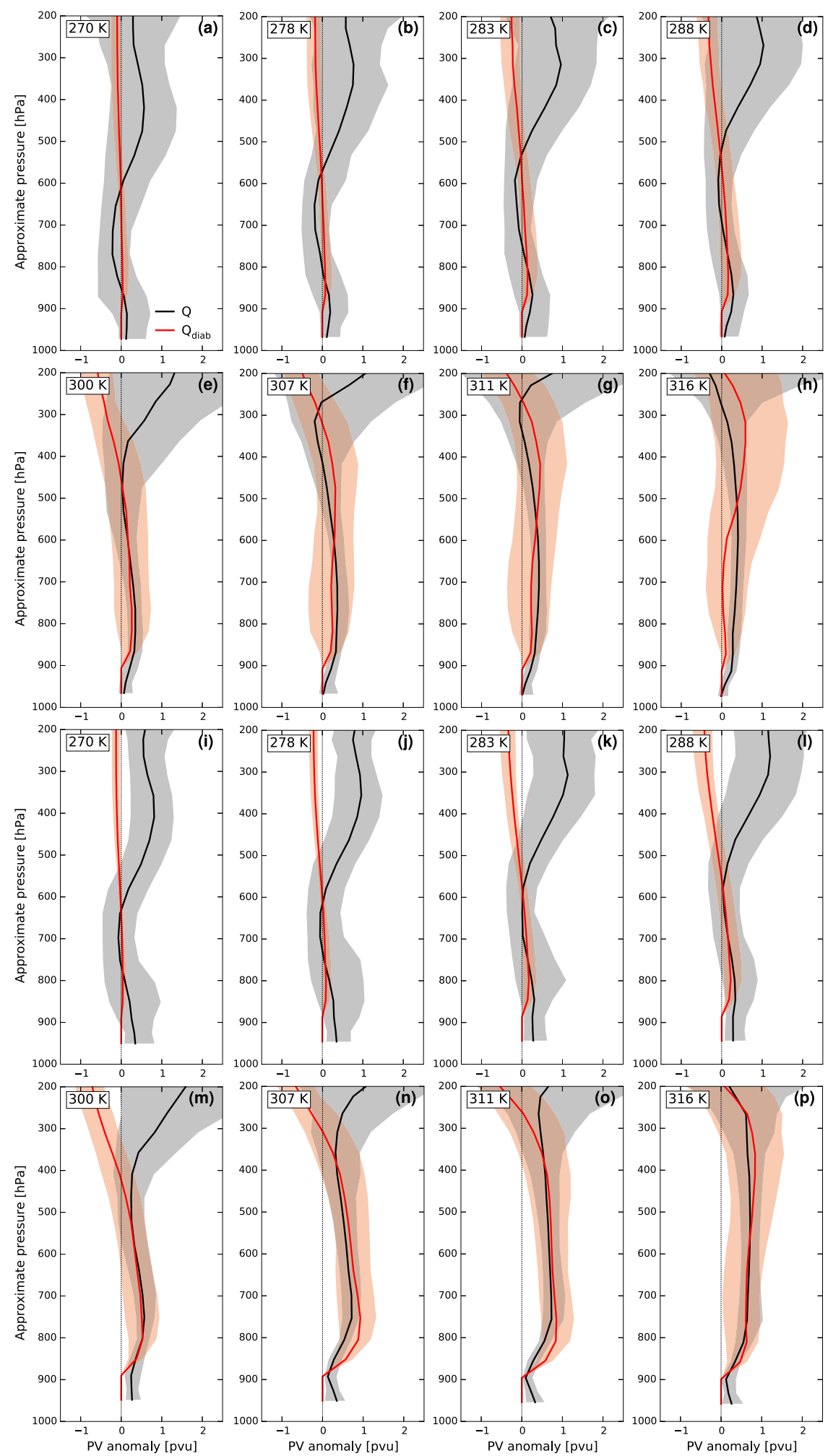

FIG. 5. Vertical profiles of the modeled PV anomaly $Q$ (PVU; black lines) and diagnosed diabatic PV $Q_{\text {diab }}$ (PVU; red lines) averaged over the effective cyclone area at the time of the lowest SLP minimum for the SLP-based (a)-(h) moderate and (i)-(p) intense cyclones in selected climates with global mean surface air temperatures $(\mathrm{K})$ indicated in the upper-left box in each panel. The solid lines show the median, and the shading indicates the range between the corresponding 5 th and 95th percentiles. Note these profiles are not rescaled with their relative effective cyclone area size. 
Both for the moderate and intense cyclones of the reference simulation (Figs. 5d,1), diabatic PV reaches similar values as the PV anomaly in the lower to middle troposphere $(\sim 850-550 \mathrm{hPa})$, but not in the boundary layer (below $900 \mathrm{hPa}$ ). The local minimum of $Q$ in the middle troposphere $(\sim 650 \mathrm{hPa})$ of the moderate cyclones is not properly reproduced by the diabatic PV profile. In the upper troposphere, the diabatic PV profile becomes negative and thus deviates strongly from the PV anomaly profile. Toward the colder climates, diabatic PV in the lower to middle troposphere decreases in a similar way as the PV anomaly (Figs. 5a-c,i-k). However, the vertical decrease in the PV anomaly and the associated negative midtropospheric PV minimum in the moderate cyclones (Figs. 5a-c) are not reproduced by the diabatic PV profiles. Toward the warmer climates, the increase of the lower- to midtropospheric PV anomaly is properly captured by the diabatic PV profiles both with respect to amplitude and structure for the intense cyclones (Figs. $5 \mathrm{~m}-\mathrm{p}$ ), but less so for the moderate cyclones (Figs. 5e-h). In the warmest climates, diabatic PV is smaller than the PV anomaly in the lower troposphere and larger in the upper troposphere for the moderate cyclones (Figs. 5g,h), and slightly higher than the PV anomaly in the lower troposphere for the intense cyclones (Figs. 5n,o). Particularly for the moderate cyclones in the warmest climate with $T_{G}=316 \mathrm{~K}$ (Fig. $5 \mathrm{~h}$ ), there is a striking structural mismatch between the diabatic PV and PV anomaly profiles, with diabatic PV being near zero in the lower and middle troposphere and relatively high in the upper troposphere.

To summarize the results from Fig. 5 for the lower to middle troposphere, Fig. 6 shows the mass-weighted vertical average between 900 and $600 \mathrm{hPa}$ of the modeled PV anomaly $Q$ and diagnosed diabatic PV $Q_{\text {diab }}$ for the moderate and intense cyclones as a function of $T_{G}$. The PV values are rescaled with the relative effective cyclone area size following Eq. (2). The lower- to midtropospheric PV anomalies in the moderate cyclones (Fig. 6a) are slightly negative in the coldest climates, followed by an approximately linear increase toward warmer climates, and a leveling off and ultimately a slight decrease in the warmest climates. The maximum PV anomaly in the climate with $T_{G}=304 \mathrm{~K}$ is approximately 3 times larger than the value in the reference climate $\left(T_{G}=288 \mathrm{~K}\right)$, and the spread of the PV anomalies decreases with $T_{G}$. Consistent with the vertical profiles (see Fig. 5), lower- to midtropospheric diabatic PV changes very similarly with $T_{G}$ and reaches a maximum in the same climate $\left(T_{G}=304 \mathrm{~K}\right)$. However, it is not negative in the coldest climates and lower in the warmest climates because of the aforementioned structural mismatch indicated by the vertical profiles. In contrast to the PV anomaly, the spread of diabatic PV increases with $T_{G}$. The lower- to midtropospheric PV anomaly of the intense cyclones, shown in Fig. 6b, exhibits a qualitatively similar nonmonotonic sensitivity to $T_{G}$ as for the moderate cyclones, but with a substantially stronger increase toward warmer climates. The maximum is reached in a similarly warm climate as for the moderate cyclones $\left(T_{G}=307 \mathrm{~K}\right)$ and the spread also decreases with $T_{G}$ but is larger than for the moderate cyclones. Also for the intense cyclones, lower- to midtropospheric diabatic PV changes very similarly as the PV anomaly and reaches its maximum in the same climate with $T_{G}=307 \mathrm{~K}$. The lower values in the climates slightly warmer than the reference climate and higher values in some of the warmest climates mainly result from the slight under- and overestimation, respectively, of the corresponding vertical profiles in the lower troposphere (see Fig. 5).

In conclusion, Figs. 5 and 6 demonstrate that the increase of the lower- to midtropospheric PV anomaly with $T_{G}$, which is substantially stronger in the intense cyclones but reaches a maximum in similar, very warm climates for both cyclone subsets, can be explained to a large degree by a corresponding increase of cyclonerelated LH and thus the strength of diabatic PV generation. Comparing this sensitivity of lower-tropospheric diabatic PV to $T_{G}$ (Fig. 6) with the sensitivity of cyclone intensity measured in terms of lower-tropospheric relative vorticity to $T_{G}$ (Fig. $4 \mathrm{~b}$ ) demonstrates the role of LH for the intensity change of the two cyclone subsets: the increase of $\mathrm{LH}$ and thus lower-tropospheric diabatic $\mathrm{PV}$ in the moderate cyclones toward very warm climates is too weak to further increase their intensity (i.e., the intensity maximum is already reached in a climate only slightly warmer than the present day), because MAPE concurrently decreases toward very warm climates (O'Gorman and Schneider 2008a). In contrast, the substantially stronger increase of LH and thus lowertropospheric diabatic PV in the intense cyclones is strong enough to overcompensate for the reduction in MAPE and thus further increases their intensity toward very warm climates (note that $Q_{\text {diab }}$ and lowertropospheric relative vorticity reach their maximum in the same climate with $T_{G}=307 \mathrm{~K}$; see Figs. $6 \mathrm{~b}$ and $4 \mathrm{~b}$ ). This distinct role of LH for the intensity of the intense compared to the moderate cyclones has already been hypothesized by Pfahl et al. (2015) and is here confirmed quantitatively with the help of our PV diagnostic. In addition to the changes in $\mathrm{LH}$ with increasing $T_{G}$, changes in the cyclone-related positive surface potential temperature anomaly (Hoskins et al. 1985) might further contribute to the changes in cyclone intensity. However, case studies (e.g., Stoelinga 1996; Ahmadi-Givi et al. 2004) have 

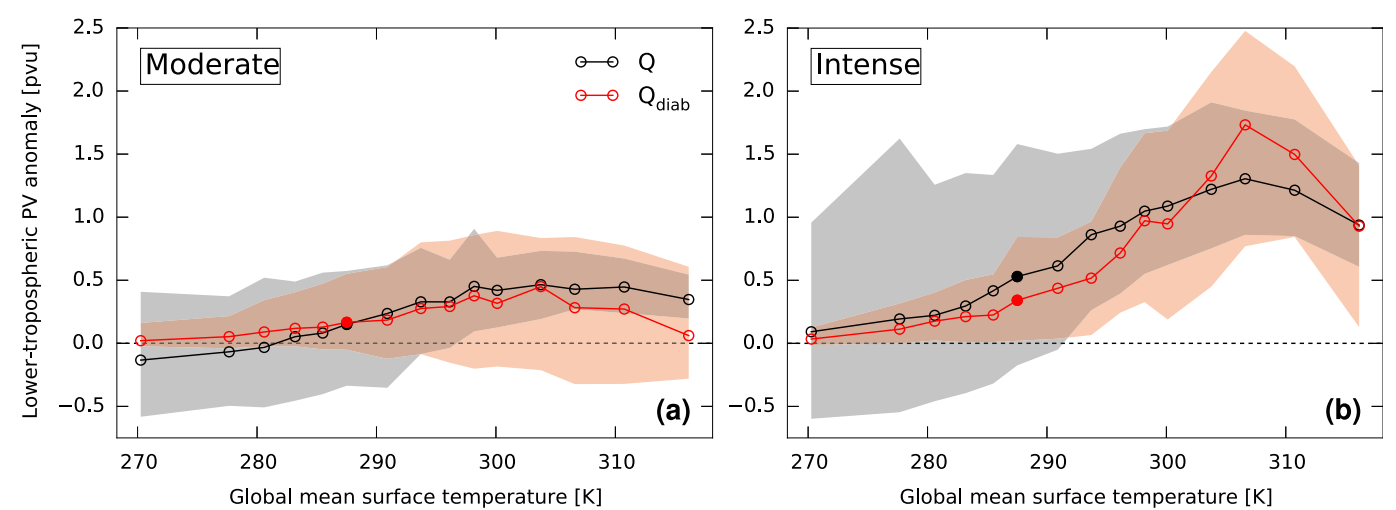

FIG. 6. Mass-weighted vertical averages of the modeled PV anomaly $Q$ (PVU; black lines) and diagnosed diabatic PV $Q_{\text {diab }}$ (PVU; red lines) between 900 and $600 \mathrm{hPa}$ at the time of the lowest SLP minimum as a function of global mean surface air temperature (K) for the SLP-based (a) moderate and (b) intense cyclones. All values have been rescaled with their corresponding relative effective cyclone area size following Eq. (2). The solid lines show the median, and the shading indicates the range between the corresponding 5 th and 95th percentiles. The filled circles show the median for the reference climate $\left(T_{G}=288 \mathrm{~K}\right)$.

indicated that typically the relative contribution of the surface temperature anomaly to cyclone intensity is substantially smaller than the contribution of the lowertropospheric diabatic PV anomaly as well as the uppertropospheric PV structure. This is likely still the case in warmer climates, in which the surface meridional temperature gradient and thus also the temperature anomalies typically associated with extratropical cyclones are reduced, although a detailed quantification would be required to confirm this. Relating our results further to the sensitivity of cyclone-related near-surface wind speed and precipitation to $T_{G}$ (Fig. 4) finally demonstrates the role of $\mathrm{LH}$ for changes in cyclone impacts: as already discussed in section $3 \mathrm{~b}(2)$, near-surface wind speed (Fig. 4d) correlates almost perfectly with the intensity measured in terms of lower-tropospheric relative vorticity (Fig. $4 \mathrm{~b} ; r=0.96$ for the moderate and $r=0.98$ for the intense cyclones). Near-surface wind speed thus has a qualitatively similar climate sensitivity as the lower-tropospheric PV anomaly and diagnosed diabatic PV for the intense cyclones (Fig. 6b; $r=0.75$ with $Q$ and $r=0.62$ with $Q_{\text {diab }}$ ) but less so for the moderate cyclones (Fig. 6a; $r=0.25$ with $Q$ and $r=0.53$ with $Q_{\text {diab }}$ ). Consequently, the increase of LH and thus lowertropospheric diabatic PV in the intense cyclones can also largely explain their increase in near-surface wind speed toward very warm climates. The increase of $\mathrm{LH}$ and thus lower-tropospheric diabatic PV in the moderate cyclones, however, is too weak to further increase their near-surface wind speed. The variations in cyclonerelated precipitation with $T_{G}$ (Fig. $4 \mathrm{c}$ ) are very similar to the variations in the lower-tropospheric PV anomaly and diagnosed diabatic PV for both cyclone subsets (Fig. 6). The corresponding correlation coefficients of precipitation are 0.99 with $Q$ and 0.85 with $Q_{\text {diab }}$ for the moderate cyclones and 0.98 with $Q$ and 0.98 with $Q_{\text {diab }}$ for the intense cyclones. A strong correlation between changes in lower-tropospheric diabatic PV and precipitation has already been found for the COSMO surrogate climate change simulations [see section $3 a(2)$ ]. Our PV diagnostic thus allows us to explicitly link the effect of a change in LH to the dynamics of cyclones through changes in PV, and, moreover, to demonstrate that precipitation is a sufficient proxy to represent changes in LH at least in these highly idealized climates. Relating the strongly correlated, nonmonotonic changes of lower-tropospheric diabatic PV and precipitation to the monotonic (close to exponential) increase of cyclonerelated vertically integrated water vapor (not shown) finally demonstrates that an increase in moisture availability alone is not sufficient to predict changes in the dynamics and impacts of cyclones.

To test the sensitivity of our conclusions to the intensity measure used to define the two cyclone subsets, Fig. 7 shows the results of the PV diagnostic for the moderate and intense cyclones defined in terms of lower-tropospheric relative vorticity [see section $2 \mathrm{c}(2)$ for details]. They are qualitatively similar as for the SLPbased cyclone subsets (see Fig. 6), and the $Q$ and $Q_{\text {diab }}$ curves match even better over a wide range of climates. However, the maxima of lower-tropospheric diabatic $\mathrm{PV}$ and thus the PV anomaly in the intense cyclones shift toward a cooler climate with $T_{G}=300 \mathrm{~K}$ (the still existing local $Q_{\text {diab }}$ maximum at $T_{G}=307 \mathrm{~K}$ mainly results from the overestimation of our PV diagnostic explained above), whereas the maxima for the moderate cyclones are reached in similar climates. Comparing Fig. 7 to the sensitivity of cyclone intensity measured in terms of 

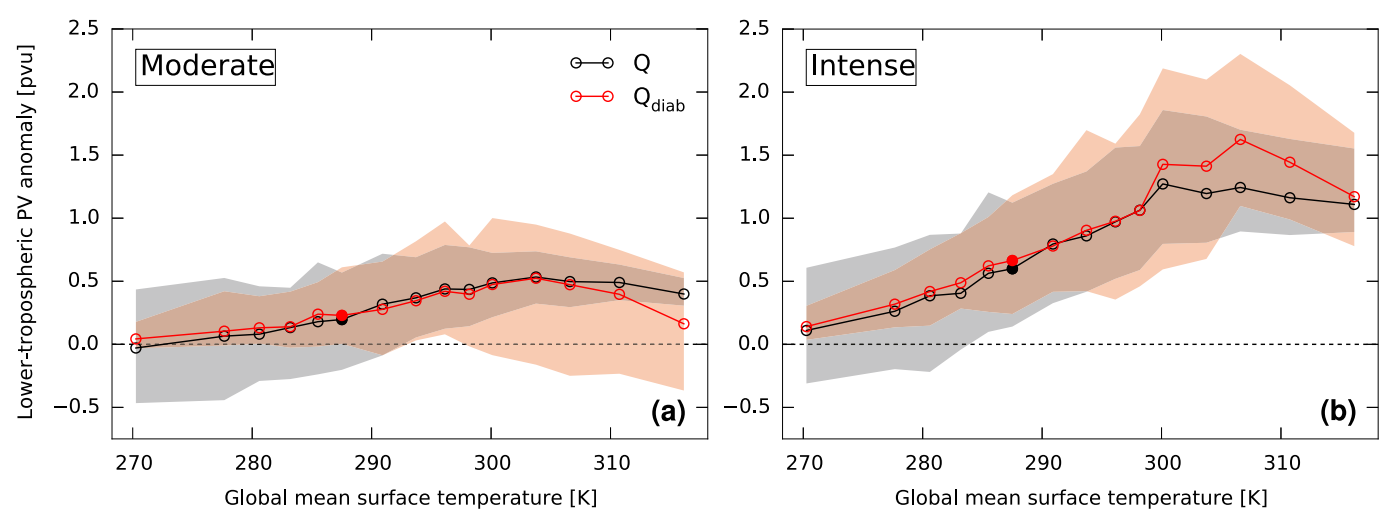

FIG. 7. As in Fig. 6, but for (a) the moderate and (b) the intense cyclones defined in terms of lower-tropospheric relative vorticity [see section $2 \mathrm{c}(2)$ for details]. Accordingly, the values at the time of the maximum relative vorticity are shown.

lower-tropospheric relative vorticity of the vorticitybased cyclone subsets (as for Fig. 7 at the time of the maximum vorticity; not shown) demonstrates that our general conclusions about the distinct role of $\mathrm{LH}$ for intense and moderate cyclones are robust, although the climates, in which the intensity maxima are reached, are sensitive to the definition of the cyclone subsets: the substantially stronger increase of LH-induced lowertropospheric PV generation in the intense cyclones shifts their intensity maximum toward a warmer climate ( $T_{G}=300 \mathrm{~K}$, where also $Q_{\text {diab }}$ and $Q$ are at their maximum) compared to the moderate cyclones. However, the intensity maximum of the moderate cyclones occurs in a slightly warmer climate with $T_{G}=296 \mathrm{~K}$ (instead of $T_{G}=294 \mathrm{~K}$ for the SLP-based moderate cyclones) and thus closer to the climate in which the intense cyclones reach their intensity maximum. This might be due to the slightly stronger LH in the vorticity-based compared to the SLP-based moderate cyclones (see the generally larger $Q_{\text {diab }}$ and $Q$ values in Fig. 7a compared to Fig. 6a).

In addition to demonstrating the distinct role of $\mathrm{LH}$ for the intensity and impact changes of the intense and moderate cyclones, the application of our PV diagnostic also highlights some further interesting aspects: in the moderate cyclones of the coldest climates, the diabatic PV values of approximately zero do not correspond to the negative PV anomalies in the lower to middle troposphere (see Fig. $6 \mathrm{a}$ and, regarding the spread, also Fig. 7a). We thus hypothesize that these negative anomalies originate from fundamentally different PV background states in the coldest climates (induced by anomalously strong static stability in the lower troposphere of the higher latitudes; see Pfahl et al. 2015, their Fig. 1a): due to the relatively large meridional gradients of lower- to midtropospheric PV in the coldest climates (Büeler 2017, their Figs. 4.3a and 4.4a), the adiabatic latitudinal displacement of air masses within cyclones creates larger PV anomalies than in warmer climates with a weaker meridional PV gradient. This adiabatic origin of the negative PV anomalies in the coldest climates is consistent with the fact that the corresponding lower- to midtropospheric diabatic PV values (median and spread) are close zero. In the warmer climates, the expansion of the lower-tropospheric PV anomaly maximum into the middle troposphere, accompanied by a shrinking of the midtropospheric PV anomaly minimum (see Fig. 5), can be explained with our PV diagnostic: by reproducing this structural change, the diabatic PV profiles demonstrate that diabatic PV generation in the warmer climates is not only confined to the lower troposphere anymore, but extends into the middle and upper troposphere. The resulting PV anomaly profiles could thus be referred to as "diabatic PV towers," which resemble the profiles of tropical cyclones (e.g., Wu and Kurihara 1996). Most likely, they reflect the shift from predominantly dry-baroclinically driven cyclones in present-day like climates toward predominantly diabatically driven vortices, so-called diabatic Rossby vortices (e.g., Moore and Montgomery 2004, 2005) or diabatic Rossby waves (e.g., Snyder and Lindzen 1991; Parker and Thorpe 1995; Boettcher and Wernli 2013), in the warmest climates, as it has been found by O'Gorman et al. (2018) in the same idealized GCM simulations as well as by Tierney et al. (2018) in baroclinic life cycle experiments of warmer climates. The obvious mismatch between diabatic PV and the PV anomalies in the moderate cyclones of the warmest climates $\left(T_{G}=\right.$ 311 and $316 \mathrm{~K}$; see Figs. 6a and 7a) indicates that our PV diagnostic is not able to reproduce lower- to midtropospheric PV in these conditions, even though it is most likely of diabatic origin. This might result from the weak intensity of the cyclones in these extreme climates (see Figs. 4a,b): their lower-tropospheric regions with diabatic PV generation are associated with vertical 
updrafts that are too weak to be fully captured by the vertical wind velocity threshold $W$ applied in the PV diagnostic [see section 2c(3)]. The maximum vertical wind velocities in these cyclones occur at much higher altitudes $(\sim 300 \mathrm{hPa}$; not shown), where they are strong enough to be captured by the PV diagnostic and thus result in a signal in the diabatic PV profiles (see Fig. 5h).

\section{Summary and conclusions}

We have systematically quantified the effect of changes in latent heating $(\mathrm{LH})$ on the dynamics, intensity, and impacts of extratropical cyclones in two conceptually different sets of idealized climate change simulations: regional COSMO surrogate climate change simulations of a spatially homogeneously $4-\mathrm{K}$-warmer and thus moister climate and idealized GCM simulations of a range of very cold to very warm aquaplanet climates, which are associated with more realistic, spatially heterogeneous temperature changes. This has been done with a novel PV diagnostic that has been introduced and evaluated in Büeler and Pfahl (2017). It makes use of the nonconservation of $\mathrm{PV}$ in the presence of diabatic processes and explicitly calculates the LH-induced fraction of the positive lowertropospheric PV anomaly based on a set of simplifying assumptions.

Applying our PV diagnostic to the 12 moderate to intense Northern Hemisphere cyclones from the COSMO surrogate climate change simulations has yielded the following results: enhanced LH associated with the higher temperature and thus moisture content amplifies the positive lower-tropospheric PV anomaly of both moderate and intense cyclones by intensifying diabatic PV generation. This amplification leads to a stronger intensification of the cyclones by enhancing cyclonic circulation in the lower troposphere, which, in most cases, results in a higher cyclone intensity, stronger near-surface wind gusts, and, in combination with the higher moisture content, more precipitation. The correlation between enhanced LH and lower-tropospheric PV is most robust from an average perspective (mean increase of lowertropospheric modeled PV of 0.11 PVU and lowertropospheric diagnosed diabatic PV of $0.13 \mathrm{PVU}$ ). Nevertheless, the strong case-to-case variability of the changes in lower-tropospheric PV and thus in cyclone intensity and impacts can partly be explained by consistent changes in diabatic PV generation and thus in LH. Deviations from this relationship for individual cyclones are assumed to originate mainly from the simplified assumptions underlying our PV diagnostic, but also from further physical processes apart from LH affecting cyclones in a warmer climate. Our results further indicate that intense diabatically driven cyclones such as Xynthia have the potential to be substantially more devastating if occurring in a future warmer climate.

Applying our PV diagnostic to the cyclones of the idealized GCM simulations has shown that the role of $\mathrm{LH}$ is different if the changes in moisture and thus $\mathrm{LH}$ are embedded in further changes in the horizontal and vertical temperature structure: $\mathrm{LH}$-induced diabatic $\mathrm{PV}$ generation and thus the lower-tropospheric PV anomaly intensify with increasing global mean surface air temperature and reach a maximum in climates substantially warmer than present-day. This increase is considerably stronger in the most intense compared to the moderate cyclones defined in terms of minimum SLP. In contrast, mean available potential energy (MAPE) changes nonmonotonically with $T_{G}$, reaching a maximum in a climate similar to present-day but decreasing toward substantially warmer climates (O'Gorman and Schneider 2008a). Consequently, the increase of LH (and thus lowertropospheric diabatic PV) in the moderate cyclones toward very warm climates is too weak to overcompensate for the counteracting reduction in MAPE, which results in a decrease of their intensity that is consistent with a reduction in near-surface EKE found by O'Gorman and Schneider (2008a). The impacts of the moderate cyclones consequently change twofold: near-surface wind speed also decreases, whereas precipitation, which is directly linked to $\mathrm{LH}$, further increases toward very warm climates. In contrast, the substantially stronger increase of LH in the intense cyclones toward very warm climates is strong enough to overcompensate for the reduction in MAPE and thus leads to a further increase of their intensity, near-surface wind speed, and precipitation, as it has been hypothesized by Pfahl et al. (2015) and confirmed here. Qualitatively similar results are obtained when the moderate and intense cyclones are defined in terms of maximum lower-tropospheric relative vorticity along the cyclone track, with the exception that the maximum LH-induced lower-tropospheric PV generation and thus intensity of the intense cyclones is reached in a slightly colder climate than for the SLP-based intense cyclones, whereas the influence of LH on the moderate cyclones is slightly larger. This demonstrates that, in principle, increasing cyclonerelated LH can further increase the intensity of both intense and moderate cyclones toward climates warmer than the present day. In which climate their intensity maxima occur, however, primarily depends on how strongly cyclone-related LH increases, which to some degree also depends on how intense and moderate cyclones are defined.

The results from the GCM simulations, complemented by the results from the COSMO surrogate climate change 
simulations, thus demonstrate that a tug of war between enhanced LH and reduced MAPE might ultimately decide on how cyclone intensity will change in a future climate. Whether a dampening effect of enhanced LH on cyclone intensity, as it has been found in individual idealized case studies by Kirshbaum et al. (2018) and Rantanen et al. (2019), also acts in our simulations and, if so, how it influences this tug of war, would require a more detailed investigation of the structural characteristics of both the moderate and intense cyclones. Furthermore, the tug of war might change to the favor of LH in GCM simulations with higher spatial resolutions. To test this hypothesis, we have also applied our diagnostics to a set of simulations with higher horizontal resolutions of T127 ( $\sim 157 \mathrm{~km}$ at the equator) and T170 $(\sim 118 \mathrm{~km}$ at the equator), but we did not show the results here because they are similar to the T85 simulations. However, it is very likely that the highest resolution investigated here (T170) is still too coarse to resolve important mesoscale processes associated with LH, as earlier studies have shown (e.g., Willison et al. 2015). Finally, comprehensive GCM simulations project very different changes in intense cyclone activity in the Northern (e.g., Chang 2018; Zappa et al. 2013b) compared to the Southern Hemisphere (e.g., Chang 2017), which both do not clearly correlate with changes in MAPE (Chang 2017, 2018). It is thus likely that changes in $\mathrm{LH}$ are an additional process that should be considered to fully understand these differential storm-track responses.

A common result of both the COSMO surrogate climate change and the idealized GCM simulations is that the increase in LH-induced diabatic PV generation correlates well with changes in lower-tropospheric relative vorticity but much less well with changes in the SLP minimum. Also Rantanen et al. (2019) showed that EKE and the SLP minimum of an idealized cyclone can change in opposite directions in a 6-K-warmer environment. This result confirms previous studies highlighting the importance of using different intensity measures for studying storm-track changes in a future climate (e.g., Bengtsson et al. 2009; Ulbrich et al. 2009; Chang 2014).

Designing a PV diagnostic based on a set of simplifying assumptions has allowed us to systematically quantify effects of LH in cyclones in idealized simulations of different climates. However, these assumptions are associated with certain drawbacks [e.g., the steadystate assumption hampers the applicability of our PV diagnostic to periods of strong cyclone intensification; see Büeler and Pfahl (2017) for more details]. Furthermore, the need to adapt certain thresholds and parameters of the PV diagnostic to the targeted model simulations complicates the comparison of diagnosed diabatic PV among different datasets in a quantitative way. Applying alternative diagnostics of $\mathrm{LH}$ in cyclones [such as the methods by Fink et al. (2012), Azad and Sorteberg (2014), or Rantanen et al. (2017)] on the same climatological datasets used here would thus be useful to better understand the robustness of some of our findings.

Despite the idealized characteristics of our simulations, our findings have some implications considering the improvement of storm-track predictions for a future climate: first, it is crucial to investigate the mean storm track and its extreme tail separately, because intense cyclones may respond differently to an increase in LH. This requires feature-based diagnostic methods such as the one used in this study in addition to the widely used Eulerian diagnostics such as MAPE and EKE. Second, it is important to further improve the representation of LH in comprehensive GCMs both by increasing spatial resolution and improving parameterizations in order to predict changes in the extreme tail of the storm tracks, which include high-impact events such as Cyclone Xynthia, correctly.

Applying our PV diagnostic to comprehensive GCM simulations would be a logical next step to investigate whether our results also hold in more realistic climate change scenarios. Such simulations account for further important processes that are missing in the idealized GCM used here, such as changes in land-ocean temperature differences and sea ice.

Acknowledgments. We are thankful to Heini Wernli for his support and the fruitful inputs throughout the project. We further thank Paul O'Gorman and Martin Singh for providing us with the idealized GCM simulations, Michael Sprenger for his technical support, ECMWF and MeteoSwiss for granting access to ECMWF analysis data, and Christian Grams for his support during the end phase. We thank the three anonymous reviewers for their constructive comments that helped us to improve this publication. D. Büeler acknowledges funding primarily by the Swiss National Science Foundation (Project 200021_149140) and, during the finishing phase, by the Helmholtz Young Investigator Group "SPREADOUT" (VH-NG-1243).

\section{REFERENCES}

Ahmadi-Givi, F., G. C. Graig, and R. S. Plant, 2004: The dynamics of a midlatitude cyclone with very strong latent-heat release. Quart. J. Roy. Meteor. Soc., 130, 295-323, https://doi.org/ 10.1256/qj.02.226.

Azad, R., and A. Sorteberg, 2014: The vorticity budgets of North Atlantic winter extratropical cyclone life cycles in MERRA 
reanalysis. Part I: Development phase. J. Atmos. Sci., $\mathbf{7 1}$, 3109-3128, https://doi.org/10.1175/JAS-D-13-0267.1.

Bengtsson, L., K. I. Hodges, and N. Keenlyside, 2009: Will extratropical storms intensify in a warmer climate? J. Climate, 22 , 2276-2301, https://doi.org/10.1175/2008JCLI2678.1.

Berrisford, P., 1988: Potential vorticity in extratropical cyclones. Ph.D. thesis, University of Reading, 168 pp.

Binder, H., M. Boettcher, H. Joos, and H. Wernli, 2016: The role of warm conveyor belts for the intensification of extratropical cyclones in Northern Hemisphere winter. J. Atmos. Sci., 73, 3997-4020, https://doi.org/10.1175/JAS-D-15-0302.1.

Boettcher, M., and H. Wernli, 2013: A 10-yr climatology of diabatic Rossby waves in the Northern Hemisphere. Mon. Wea. Rev., 141, 1139-1154, https://doi.org/10.1175/MWR-D-12-00012.1.

Booth, J. F., S. Wang, and L. Polvani, 2013: Midlatitude storms in a moister world: lessons from idealized baroclinic life cycle experiments. Climate Dyn., 41, 787-802, https://doi.org/10.1007/ s00382-012-1472-3.

Büeler, D., 2017: Potential vorticity diagnostics to quantify effects of latent heating in extratropical cyclones: Methodology and application to idealized climate change simulations. Ph.D. thesis, ETH Zurich, 166 pp., https://doi.org/10.3929/ethz-b000250887.

— effects of latent heating in extratropical cyclones. Part I: Methodology. J. Atmos. Sci., 74, 3567-3590, https://doi.org/ 10.1175/JAS-D-17-0041.1.

Campa, J., and H. Wernli, 2012: A PV perspective on the vertical structure of mature midlatitude cyclones in the Northern Hemisphere. J. Atmos. Sci., 69, 725-740, https://doi.org/10.1175/ JAS-D-11-050.1.

Catto, J. L., L. C. Shaffrey, and K. I. Hodges, 2011: Northern Hemisphere extratropical cyclones in a warming climate in the HiGEM high-resolution climate model. J. Climate, 24, 53365352, https://doi.org/10.1175/2011JCLI4181.1.

Champion, A. J., K. I. Hodges, L. O. Bengtsson, N. S. Keenlyside, and M. Esch, 2011: Impact of increasing resolution and a warmer climate on extreme weather from Northern Hemisphere extratropical cyclones. Tellus, 63A, 893-906, https:// doi.org/10.1111/j.1600-0870.2011.00538.x.

Chang, E. K. M., 2014: Impacts of background field removal on CMIP5 projected changes in Pacific winter cyclone activity. J. Geophys. Res. Atmos., 119, 4626-4639, https://doi.org/10.1002/ 2013JD020746.

_ 2017: Projected significant increase in the number of extreme extratropical cyclones in the Southern Hemisphere. J. Climate, 30, 4915-4935, https://doi.org/10.1175/JCLI-D-16-0553.1.

- 2018: CMIP5 projected change in Northern Hemisphere winter cyclones with associated extreme winds. J. Climate, $\mathbf{3 1}$, 6527-6542, https://doi.org/10.1175/JCLI-D-17-0899.1.

— Y. Y. Guo, X. Xia, and M. Zheng, 2013: Storm-track activity in IPCC AR4/CMIP3 model simulations. J. Climate, 26, 246-260, https://doi.org/10.1175/JCLI-D-11-00707.1.

Colle, B. A., J. F. Booth, and E. K. M. Chang, 2015: A review of historical and future changes of extratropical cyclones and associated impacts along the US East Coast. Curr. Climate Change Rep., 1, 125-143, https://doi.org/10.1007/s40641-015-0013-7.

Dacre, H. F., and S. L. Gray, 2013: Quantifying the climatological relationship between extratropical cyclone intensity and atmospheric precursors. Geophys. Res. Lett., 40, 2322-2327, https://doi.org/10.1002/grl.50105.

Davis, C. A., 1992: A potential-vorticity diagnosis of the importance of initial structure and condensational heating in observed extratropical cyclogenesis. Mon. Wea. Rev., 120, 2409-2428, https://doi.org/10.1175/1520-0493(1992)120<2409:APVDOT> 2.0.CO;2.

_ , and K. A. Emanuel, 1991: Potential vorticity diagnostics of cyclogenesis. Mon. Wea. Rev., 119, 1929-1953, https://doi.org/ 10.1175/1520-0493(1991)119<1929:PVDOC>2.0.CO;2.

Fink, A. H., S. Pohle, J. G. Pinto, and P. Knippertz, 2012: Diagnosing the influence of diabatic processes on the explosive deepening of extratropical cyclones. Geophys. Res. Lett., 39, L07803, https://doi.org/10.1029/2012GL051025.

Frei, C., C. Schär, D. Lüthi, and H. C. Davies, 1998: Heavy precipitation processes in a warmer climate. Geophys. Res. Lett., 25, 1431-1434, https://doi.org/10.1029/98GL51099.

Frierson, D. M. W., I. M. Held, and P. Zurita-Gotor, 2006: A grayradiation aquaplanet moist GCM. Part I: Static stability and eddy scale. J. Atmos. Sci., 63, 2548-2566, https://doi.org/ 10.1175/JAS3753.1.

Held, I. M., and B. J. Soden, 2006: Robust responses of the hydrological cycle to global warming. J. Climate, 19, 5686-5699, https://doi.org/10.1175/JCLI3990.1.

Hoskins, B. J., M. E. McIntyre, and A. W. Robertson, 1985: On the use and significance of isentropic potential vorticity maps. Quart. J. Roy. Meteor. Soc., 111, 877-946, https://doi.org/ 10.1002/qj.49711147002.

Kirshbaum, D. J., T. M. Merlis, J. R. Gyakum, and R. McTaggartCowan, 2018: Sensitivity of idealized moist baroclinic waves to environmental temperature and moisture content. J. Atmos. Sci., 75, 337-360, https://doi.org/10.1175/JAS-D17-0188.1.

Knutti, R., and J. Sedláček, 2013: Robustness and uncertainties in the new CMIP5 climate model projections. Nat. Climate Chang., 3, 369-373, https://doi.org/10.1038/nclimate1716.

Kröner, N., S. Kotlarski, E. Fischer, D. Lüthi, E. Zubler, and C. Schär, 2017: Separating climate change signals into thermodynamic, lapse-rate and circulation effects: Theory and application to the European summer climate. Climate Dyn., 48, 3425-3440, https://doi.org/10.1007/s00382-016-3276-3.

Kuo, Y.-H., M. A. Shapiro, and E. G. Donall, 1991: The interaction between baroclinic and diabatic processes in a numerical simulation of a rapidly intensifying extratropical marine cyclone. Mon. Wea. Rev., 119, 368-384, https://doi.org/10.1175/ 1520-0493(1991)119<0368:TIBBAD > 2.0.CO;2.

Lackmann, G. M., 2015: Hurricane Sandy before 1900 and after 2100. Bull. Amer. Meteor. Soc., 96, 547-560, https://doi.org/ 10.1175/BAMS-D-14-00123.1.

Marciano, C. G., G. M. Lackmann, and W. A. Robinson, 2015: Changes in U.S. East Coast cyclone dynamics with climate change. J. Climate, 28, 468-484, https://doi.org/10.1175/JCLID-14-00418.1.

Martínez-Alvarado, O., S. L. Gray, and J. Methven, 2016: Diabatic processes and the evolution of two contrasting summer extratropical cyclones. Mon. Wea. Rev., 144, 3251-3276, https:// doi.org/10.1175/MWR-D-15-0395.1.

Michaelis, A. C., J. Willison, G. M. Lackmann, and W. A. Robinson, 2017: Changes in winter North Atlantic extratropical cyclones in high-resolution regional pseudo-global warming simulations. J. Climate, 30, 6905-6925, https://doi.org/ 10.1175/JCLI-D-16-0697.1.

Moore, R. W., and M. T. Montgomery, 2004: Reexamining the dynamics of short-scale, diabatic Rossby waves and their role in midlatitude moist cyclogenesis. J. Atmos. Sci., 61, 754-768, https://doi.org/10.1175/1520-0469(2004)061<0754:RTDOSD> 2.0.CO;2. 
, and — 2005: Analysis of an idealized, three-dimensional diabatic Rossby vortex: A coherent structure of the moist baroclinic atmosphere. J. Atmos. Sci., 62, 2703-2725, https:// doi.org/10.1175/JAS3472.1.

O'Gorman, P. A., 2011: The effective static stability experienced by eddies in a moist atmosphere. J. Atmos. Sci., 68, 75-90, https://doi.org/10.1175/2010JAS3537.1.

_, and T. Schneider, 2008a: Energy of midlatitude transient eddies in idealized simulations of changed climates. J. Climate, 21, 5797-5806, https://doi.org/10.1175/2008JCLI2099.1.

— and - 2008b: The hydrological cycle over a wide range of climates simulated with an idealized GCM. J. Climate, 21, 3815-3832, https://doi.org/10.1175/2007JCLI2065.1.

— T. M. Merlis, and M. S. Singh, 2018: Increase in the skewness of extratropical vertical velocities with climate warming: Fully nonlinear simulations versus moist baroclinic instability. Quart. J. Roy. Meteor. Soc., 144, 208-217, https://doi.org/10.1002/qj.3195.

Parker, D. J., and A. J. Thorpe, 1995: Conditional convective heating in a baroclinic atmosphere: a model of convective frontogenesis. J. Atmos. Sci., 52, 1699-1711, https://doi.org/ 10.1175/1520-0469(1995)052<1699:CCHIAB > 2.0.CO;2.

Pfahl, S., P. A. O'Gorman, and M. S. Singh, 2015: Extratropical cyclones in idealized simulations of changed climates. J. Climate, 28, 9373-9392, https://doi.org/10.1175/JCLI-D-14-00816.1.

Rantanen, M., J. Raïsänen, J. Lento, O. Stepanyuk, O. Räty, V. A. Sinclair, and H. Järvinen, 2017: OZO v.1.0: Software for solving a generalised omega equation and the Zwack-Okossi height tendency equation using WRF model output. Geosci. Model Dev., 10, 827-841, https://doi.org/10.5194/gmd-10-827-2017.

— _ J. Räisänen, V. A. Sinclair, and H. Järvinen, 2019: Sensitivity of idealised baroclinic waves to mean atmospheric temperature and meridional temperature gradient changes. Climate Dyn., 52, 2703-2719, https://doi.org/10.1007/s00382-018-4283-3.

Reed, R. J., G. A. Grell, and Y.-H. Kuo, 1993: The ERICA IOP 5 storm. Part II: Sensitivity tests and further diagnosis based on model output. Mon. Wea. Rev., 121, 1595-1612, https://doi.org/ 10.1175/1520-0493(1993)121<1595:TEISPI>2.0.CO;2.

Sandvik, M. I., A. Sorteberg, and R. Rasmussen, 2018: Sensitivity of historical orographically enhanced extreme precipitation events to idealized temperature perturbations. Climate Dyn., 50, 143-157, https://doi.org/10.1007/s00382-017-3593-1.

Schär, C., C. Frei, D. Lüthi, and H. C. Davies, 1996: Surrogate climate-change scenarios for regional climate models. Geophys. Res. Lett., 23, 669-672, https://doi.org/10.1029/96GL00265.

Schneider, T., P. A. O'Gorman, and X. Levine, 2010: Water vapor and the dynamics of climate changes. Rev. Geophys., 48, RG3001, https://doi.org/10.1029/2009RG000302.

Shaw, T. A., and Coauthors, 2016: Storm track processes and the opposing influences of climate change. Nat. Geosci., 9, 656665, https://doi.org/10.1038/ngeo2783.

Sherwood, S. C., and C. L. Meyer, 2006: The general circulation and robust relative humidity. J. Climate, 19, 6278-6290, https:// doi.org/10.1175/JCLI3979.1.

Shindell, D. T., D. Rind, and P. Lonergan, 1998: Increased polar stratospheric ozone losses and delayed eventual recovery owing to increasing greenhouse-gas concentrations. Nature, 392, 589592, https://doi.org/10.1038/33385.

Snyder, C., and R. S. Lindzen, 1991: Quasi-geostrophic wave-CISK in an unbounded baroclinic shear. J. Atmos. Sci., 48, 76-86, https://doi.org/10.1175/1520-0469(1991)048<0076:QGWCIA> 2.0.CO;2.
Steppeler, J., G. Doms, U. Schättler, H. W. Bitzer, A. Gassmann, U. Damrath, and G. Gregoric, 2003: Mesogamma scale forecasts using the nonhydrostatic model LM. Meteor. Atmos. Phys., 82, 75-96, https://doi.org/10.1007/ s00703-001-0592-9.

Stoelinga, M. T., 1996: A potential vorticity-based study of the role of diabatic heating and friction in a numerically simulated baroclinic cyclone. Mon. Wea. Rev., 124, 849-874, https://doi.org/ 10.1175/1520-0493(1996)124<0849:APVBSO > 2.0.CO;2.

SwissRe, 2016: Natural catastrophes and man-made disasters in 2015: Asia suffers substantial losses. Sigma Research 1/2016, https://www.swissre.com/institute/research/sigma-research/ sigma-2016-01.html.

Tierney, G., D. J. Posselt, and J. F. Booth, 2018: An examination of extratropical cyclone response to changes in baroclinicity and temperature in an idealized environment. Climate Dyn., 51, 3829-3846, https://doi.org/10.1007/s00382-0184115-5.

Trzeciak, T. M., P. Knippertz, J. S. R. Pirret, and K. D. Williams, 2016: Can we trust climate models to realistically represent severe European windstorms? Climate Dyn., 46, 3431-3451, https://doi.org/10.1007/s00382-015-2777-9.

Ulbrich, U., G. C. Leckebusch, and J. G. Pinto, 2009: Extra-tropical cyclones in the present and future climate: A review. Theor. Appl. Climatol., 96, 117-131, https://doi.org/10.1007/s00704008-0083-8.

Wernli, H., 1995: Lagrangian perspective of extratropical cyclogenesis. Ph.D. thesis, ETH Zürich, 157 pp., https://doi.org/ 10.3929/ethz-a-001442585.

— dataset (1958-2001). Part I: Novel identification method and global climatology. J. Atmos. Sci., 63, 2486-2507, https://doi.org/ 10.1175/JAS3766.1.

Willison, J., W. A. Robinson, and G. M. Lackmann, 2013: The importance of resolving mesoscale latent heating in the North Atlantic storm track. J. Atmos. Sci., 70, 2234-2250, https:// doi.org/10.1175/JAS-D-12-0226.1.

,$- \ldots$, and — 2015: North Atlantic storm-track sensitivity to warming increases with model resolution. J. Climate, $\mathbf{2 8}$, 4513-4524, https://doi.org/10.1175/JCLI-D-14-00715.1.

Wu, C.-C., and Y. Kurihara, 1996: A numerical study of the feedback mechanisms of hurricane-environment interaction on hurricane movement from the potential vorticity perspective. J. Atmos. Sci., 53, 2264-2282, https://doi.org/10.1175/15200469(1996)053<2264:ANSOTF>2.0.CO;2.

Yettella, V., and J. E. Kay, 2017: How will precipitation change in extratropical cyclones as the planet warms? Insights from a large initial condition climate model ensemble. Climate Dyn., 49, 1765-1781, https://doi.org/10.1007/s00382-016-3410-2.

Yin, J. H., 2005: A consistent poleward shift of the storm tracks in simulations of 21 st century climate. Geophys. Res. Lett., 32 , L18701, https://doi.org/10.1029/2005GL023684.

Zappa, G., L. C. Shaffrey, and K. I. Hodges, 2013a: The ability of CMIP5 models to simulate North Atlantic extratropical cyclones. J. Climate, 26, 5379-5396, https://doi.org/10.1175/JCLID-12-00501.1.

,,,--- P. G. Sansom, and D. B. Stephenson, 2013b: A multimodel assessment of future projections of North Atlantic and European extratropical cyclones in the CMIP5 climate models. J. Climate, 26, 5846-5862, https://doi.org/10.1175/ JCLI-D-12-00573.1. 